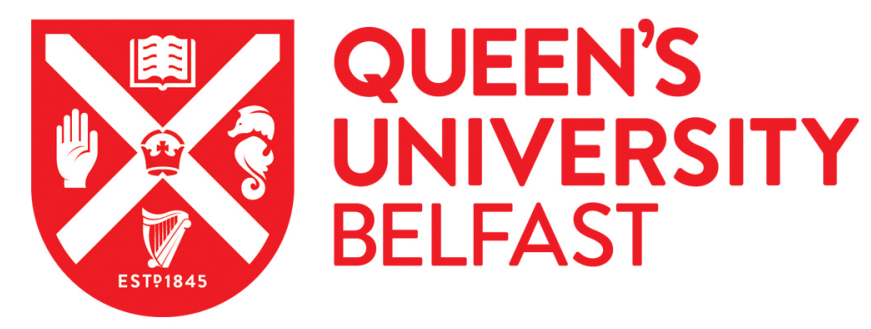

\title{
Evaluation of Crushing and Energy Absorption Characteristics of Bio- Inspired Nested Structures
}

Nikkhah, H., Baroutaji, A., Kazancı, Z., \& Arjunan, A. (2020). Evaluation of Crushing and Energy Absorption Characteristics of Bio-Inspired Nested Structures. Thin-Walled Structures, 148, [106615].

https://doi.org/10.1016/j.tws.2020.106615

\section{Published in:}

Thin-Walled Structures

\section{Document Version:}

Peer reviewed version

\section{Queen's University Belfast - Research Portal:}

Link to publication record in Queen's University Belfast Research Portal

\section{Publisher rights}

(C) 2020 Elsevier Ltd.

This manuscript version is made available under the CC-BY-NC-ND 4.0 license http://creativecommons.org/licenses/by-nc-nd/4.0/,which permits distribution and reproduction for non-commercial purposes, provided the author and source are cited.

\section{General rights}

Copyright for the publications made accessible via the Queen's University Belfast Research Portal is retained by the author(s) and / or other copyright owners and it is a condition of accessing these publications that users recognise and abide by the legal requirements associated with these rights.

Take down policy

The Research Portal is Queen's institutional repository that provides access to Queen's research output. Every effort has been made to ensure that content in the Research Portal does not infringe any person's rights, or applicable UK laws. If you discover content in the Research Portal that you believe breaches copyright or violates any law, please contact openaccess@qub.ac.uk. 
Evaluation of Crushing and Energy Absorption Characteristics of Bio-Inspired Nested Structures

$$
\text { H. Nikkhah }{ }^{1} \text {, A. Baroutaji2 }{ }^{*} \text {, Z. Kazanc1 }{ }^{3} \text { and A. Arjunan }{ }^{2}
$$

${ }^{1}$ Faculty of Engineering, School of Mechanical Engineering, University of Mohaghegh Ardabili, Ardabil, Iran

${ }^{2}$ Faculty of Science and Engineering, School of Engineering, University of Wolverhampton, Telford, UK

${ }^{3}$ Advanced Composites Research Group, School of Mechanical and Aerospace Engineering, Queen's University Belfast, Belfast, UK

\begin{abstract}
Mimicking anatomical structures like bone can aid in the development of energy absorbing structures that can achieve desirable properties. Accordingly, this study presents the analysis of tubular nested designs inspired by Haversian bone architecture. Based on this design philosophy, a total of 18 nested tube designs with various geometrical configurations were developed. Within each design, the effect of reinforcement walls on the crashworthiness performance is also analysed. A finite element model, validated using quasi-static experimental tests, was used to study the crashworthiness performance and progressive deformation of the nested system. Based on the results, a multi-criteria decision-making method known as Technique of Order Preference by Similarity to Ideal Solution (TOPSIS) was employed to determine the most suitable cross-section that features high energy absorption and low impact force. Consequently, the study identified a nested tube configuration that exhibits superior crashworthiness and high energy absorbing characteristics. The bioinspired design methodology presented in this study allows the exploitation of variable nested geometries for the development of high-efficiency energy absorbing structures.
\end{abstract}

\footnotetext{
* Corresponding author. Address: School of Engineering, University of Wolverhampton, Telford Innovation Campus, Priorslee, Telford, TF2 9NT, UK. Tel.: +44 (0)1902 322981; fax: +44 (0)1902 323843.

E-mail address: ahmad.baroutaji2@mail.dcu.ie (Dr Ahmad Baroutaji).
} 
Keywords: Nested tube; Energy absorption; Dynamic loading; Bio-inspired crosssection; Multi-Criteria Decision Making Method

\section{Introduction}

Energy absorbing structure is an integral part of any vehicles to reduce the risk of high loads generated during an impact event. Thin-walled structures have been widely used as energy absorbers due to their excellent performance under dynamic and impact forces [1-6]. The energy absorption performance of thin-walled structures with different cross-sections and configurations such as square [7,8], circular [9,10], bi-tubal [11], pentagon [12], tapered [13,14], sandwich [15,16], honeycomb [17-20], windowed [21-24], multi-cell and nested [25-29] has been extensively studied in literature. The parameters of importance for such structures are the high Specific Energy Absorption (SEA) and the low initial Peak Crushing Force (PCF) which can be established using different experimental, numerical, and theoretical techniques [30-35].

Nowadays, with the ever increased interest in the balance between the safety and environmental requirements of a passenger vehicle, the demand for modern structures with higher energy absorption capacity and lighter weight has increased sharply in the automotive industry. Nested tubes systems are among the structures that have the potential to address the conflicting crashworthiness design objectives of vehicles. Nested systems can be regarded as a type of multi-cell structures where the global performance is dictated by the complex nested geometry. The nested structures, with different geometrical shapes and nesting arrangements, have received considerable research attention and their crashworthiness behaviours under axial and lateral loadings were explored in many studies.

Alavi Nia and Chahardoli [36,37] investigated the mechanical behaviour of nested multi-tubular structures under axial loading. The result of their study showed that increasing the number of tubes in a nested design leads to an increase in both SEA and Crash Force Efficiency (CFE). Similar findings were also reported by Usta and Türkmen [38] who found that the SEA values of nested structures increased as the number of tubes was increased from 1 to 5 .

Baroutaji et al. [39] studied the experimental behaviour of short length circular nested tube systems under lateral impact loading. After extending the study to investigate the influence of 
geometrical parameters concluded that the collapse load decreased with decreasing thickness and increasing the tube diameter. In addition, Olabi et al. [40] experimentally and numerically investigated the effects of side constraints and quantified its influence on the behaviour of nested tubes under lateral crushing. The study also demonstrated a good correlation between the experimental and numerical results later confirmed by theoretical, experimental and numerical investigations by Wang et al. [41] and Tran [42] as well.

Chahardoli et al [43] presented a new type of nested structure which contains two tubes with different orientations with respect to the direction of loading. In this structure, the inner tube is located vertically so it can be loaded axially while the outer tube was located horizontally in order to be loaded laterally. It was found that the nested tube absorber yields higher crush force efficiency than its individual units when they are crushed separately.

The studies on nested structures were not limited to the thin walled tubes but were also extended to other structural shapes such as shells. The dynamic deformation behaviour of 'Internally Nested Hemispherical Shell System' (INHSS) was experimentally and computationally investigated by $\mathrm{Hu}$ et al. [44]. The results showed that the dynamic deformation process and energy absorption capability of INHSS depend on the thickness and radius of the inner shell. Crashworthiness optimisation of nested and concentric circular tubes under impact loading is also available in literature coupling Finite Element Method (FEM), Response Surface Models (RSM) and statistical based optimisation algorithms [45-52].

The concept of nested tubes systems was originally inspired by the structure of different natural materials such as those in plants, animals or even human bodies. Currently, there is a growing area of research on optimising the crashworthiness performance based on bio-inspired design guidelines. According to Meyers et al. [53] and Kooistra et al. [54], organic structures were shown to have superior mechanical performance that is customised to targeted requirements. For example, bamboo-inspired bionic honeycomb tubular nested structure under axial load was investigated using a dynamic drop-weight impact experiment [55]. The results showed that the SEA of nature-inspired nested tubes were substantial in comparison to the traditional designs. Furthermore, the parametric numerical simulation revealed the influence of diverse mean diameter of the tube and the length of the junction plate on the energy-absorption characteristics. 
Another interesting phenomenon observed among load-bearing tissues such as bones are successively organised nested structures [56]. Such a system known as the Haversian architecture commonly seen in cortical bone is exploited in this study. One popular scheme of Haversian inspired honeycomb-like hexagonal columns were investigated by $\mathrm{Xu}$ et al. [57] in their pioneering study and reported that wall thickness of hexagonal cells has a higher influence on crashworthiness in comparison to the thickness and hierarchical size ratios.

Generally, to the best of the authors' knowledge, all the nested structures presented in the literature consisted of tubes with the same cross-sectional shapes such as square, hexagonal or circular but with varied dimensions. Studies on the energy absorption and collapse behaviour of a nested structure composed of tubes with different geometrical cross-sectional shapes are not considered before. Consequently, this study evaluates the influence of alternative cross-section design of Haversian inspired nested tubes on their energy absorption. Furthermore, the mechanical performance of different reinforcement walls on nested tube designs is investigated using experimental and numerical techniques.

\section{Material and Methods}

\subsection{Geometrical description of bio-inspired nested tubes}

This study presents energy absorption investigation of nested tubes structures with different cross sectional shapes. The nesting arrangements of the tubes are inspired by the Haversian architecture that forms the structure of the cortical bone as shown in Figure 1. The Haversian system is consisted of multiple concentric layers of bones and each layer is known as lamella. The configuration of Haversian architecture is similar to nested structures, where the central circular tubes are surrounded by another circular arrangement.

To mimic the nested tube-like structures of the Osteon surrounding the Haversian canal, a total of 18 different nested column designs are conceived as shown in Figure 2. The global structure of the nested columns is primarily controlled by three structures representative of Osteon layers namely; inner, middle and outer tubes.

Three cross-sectional shapes namely circular, hexagonal and square were considered. In each category two variants were taken; 'with' and 'without' reinforcement walls. All the designs featured the same cross-sectional area of 1735, 860 and $432 \mathrm{~mm}^{2}$ for outer, middle and inner 
tubes respectively. The gauge thickness is $2 \mathrm{~mm}$ and the length of the reinforcement wall connecting the outer to middle and middle to inner is $68 \mathrm{~mm}$ and $98 \mathrm{~mm}$, respectively. The lengths of the inner, middle and outer columns are 128, 98 and $68 \mathrm{~mm}$, respectively as shown in Figure 3. The main advantage of using different lengths for the different components in the nested structures is decreasing the initial peak crush force as only the taller component (inner tube) will be crushed at the moment of the impact while the other components, i.e. middle and outer tubes, will be engaged in the crushing process during the later stages.

\subsection{Finite element modelling}

The Finite Element (FE) models of nested tubes were developed using LS-DYNA code to simulate the progressive compressive behaviour. All the designs were modelled using Belytschko-Lin-Tsay four-node shell elements with nine integration points through the thickness. An element size of $1 \times 1 \mathrm{~mm}$ was found to be adequate for the solution based on the mesh convergence analyses carried out. The boundary conditions were applied to recreate the physical test conditions as shown in Figure 4. The FE model is composed of upper moving plate, lower stationary plate, and the nested-tube sample. The tubes were placed in the axial orientation between the two plates. The bottom plate was fully fixed, and the top end of the tube was assumed to be free. The top rigid wall was modelled featuring a mass of $800 \mathrm{~kg}$ and constrained to impact vertically onto the column. The mass value selection of $800 \mathrm{~kg}$ ensured that all nested columns could be fully crushed at an impact velocity of $10 \mathrm{~m} / \mathrm{s}$ which is a typical value used for automobile crashworthiness applications [23]. In order to avoid penetration problems between the tube surfaces and the rigid walls, the node-to-surface contact algorithm was used for the FE model. In addition, the single-surface contact was employed to prevent interpenetration between the nested tube walls during deformation. The Coulomb friction coefficient at all contact pairs was considered 0.15 [23].

Experimental tensile tests were conducted to determine the mechanical properties of the nested tube material. Considering that the tubes are made through extrusion process which might yield an anisotropic behaviour, the tensile samples were cut from the sidewalls of the tube and in two directions including parallel to the extrusion direction and perpendicular to it (transverse). The stress-strain curves and the tensile samples are shown in Figure 5 whereas the extracted mechanical properties are tabulated in Table 1. It is evident from the figure and table that the 
AA6060-T4 alloy exhibits insignificant anisotropic behaviour where all the mechanical properties in the two directions are comparable with a maximum difference of around $7 \%$ (observed for the elastic modulus) and thus the extruded aluminium alloy can be considered as an almost isotropic material. Such material behaviour has previously been observed and reported by other researchers [58-61]. Consequently, the anisotropic material behaviour of aluminium due to extrusion process can be neglected and the mechanical properties in the extrusion direction can be considered sufficient to represent the behaviour of the tube and they can be used in the finite element model. Similar approach was considered in comparable previous investigations [62-65].

The Modified Piecewise Linear Plasticity (MPLP) material model was used to represent the aluminium alloy AA6060-T4 in the numerical model. The MPLP model provides a multilinear elastic-plastic material option which allows the stress-strain $(\sigma-\varepsilon)$ curve input. The material model featured a material density $(\rho)$ of $2700 \mathrm{~kg} / \mathrm{m}^{3}$, Young's modulus (E) of $70 \mathrm{GPa}$, Poisson's ratio $(v)$ of 0.33 and yield stress $\left(\sigma_{\text {yield }}\right)$ of $90 \mathrm{MPa}$.

\subsection{Experimental test}

In order to validate the numerical model, experimental quasi-static crush test was carried out on aluminium (AA6060-T4) tube created via extrusion and has a circular nested cross section as shown in Figure 6 (b). The diameter of the outer circle, the diameter of the inner circle, the length and the wall thickness of the validation sample were $46 \mathrm{~mm}, 23 \mathrm{~mm}, 68 \mathrm{~mm}$ and $2 \mathrm{~mm}$ respectively.

The experimental test was performed under axial loading. A universal test machine manufactured by Santam (STM-150) equipped with a $150 \mathrm{kN}$ load cell, as shown in Figure 6 (a), was used to carry out the tests. The test fixture was made up of two separate parts; the lower and the upper plates. The test specimen was placed on the lower plate while the upper plate was moved downward at a speed of $10 \mathrm{~mm} / \mathrm{min}$ to crush the specimen. The test continued until $60 \%$ of the total length of the tube was crushed. The force-displacement curves were recorded from the load cell and crosshead movement, respectively. To ensure repeatability and accuracy of the test results, three axial crushing tests were performed.

\subsection{Crashworthiness evaluation metrics}


To study the crashworthiness of the Haversian inspired nested tubes, three parameters are considered including Specific Energy Absorption (SEA), Peak Crushing Force (PCF) and the Crush Force Efficiency (CFE). These parameters are widely accepted to study the crush behaviour of thin-walled structures [42,66,67]. The Energy Absorption (EA) during the axial deformation is given by Eq. 1:

$$
E A=\int_{0}^{\delta} F(x) d x
$$

Where $F(x)$ and $\delta$ are the instantaneous load and the deformation distance of the nested tube respectively. Accordingly, the SEA is the energy absorbed by unit mass $(m)$ expressed using Eq. 2:

$$
S E A=\frac{E A}{m}
$$

For light weight crashworthiness design, the higher SEA is the main goal.

PCF represents the initial peak crush force and a lower value is preferred to prevent instant deceleration, which is undesirable for crashworthiness.

Consequently, CFE can be expressed using Eq. 3:

$$
C F E=\frac{M C F}{P C F}=\frac{E A}{\delta \times P C F}=\frac{m}{\delta} \times \frac{S E A}{P C F}
$$

Where MCF is the mean crush force, $\delta$ is the crushing distance. Generally, the higher the CFE, the better consistency can be obtained in the energy absorption throughout the collapse spectrum. As a result, an ideal structure for crashworthiness maybe defines as the one with a $100 \% \mathrm{CFE}$.

The last energy absorption indicator which is used in this study is the energy absorbing effectiveness factor $(\psi)$ [68], which can determined using Eq. 4:

$$
\psi=\frac{E A}{V \times \varepsilon_{r} \times \sigma_{o}}
$$


Where $\mathrm{V}$ is volume of the structure, $\varepsilon_{r}$ is rupture strain and $\sigma_{o}=\frac{\left(\sigma_{Y}+\sigma_{U}\right)}{2}$ is the flow stress. Considering the aluminium alloy used in this study is insensitive to strain rate, $\varepsilon_{r}$, yield stress ( $\left.\sigma_{Y}\right)$, and ultimate stress $\left(\sigma_{U}\right)$ were all obtained from static tensile tests.

\subsection{Multi-criteria decision-making method}

The decision-making requirement of the presented study requires an analysis and comparison of many variables. This includes the cross-section of the nested tubes along with the various design criteria's associated with the crashworthiness such as high SEA, low PCF and high CFE. Therefore, the selection of the best design balancing the multiple criteria by considering different choices requires a Multi-Criteria Decision Making (MCDM) exercise.

Accordingly, the Technique for Order of Preference by Similarity to Ideal Solution (TOPSIS) is implemented in this study to rank and determine the best-nested tube design. TOPSIS was developed by Hwang and Yoon [69] and requires an alternative that has the minimum and maximum distance from the positive and negative ideal solution. Therefore, using SEA, PCF, and CFE as the selected design criteria, two alternatives are assumed: the ideal alternative is the design criterion that features the best level for all the indices and the negative ideal alternative is the design criterion with the worst indices. The TOPSIS methodology, as detailed in $[69,70]$, starts with the creation of an evaluation matrix consisting of $m$ alternatives and $n$ criteria of the form shown in Eq. 5:

$$
\left(x_{i j}\right)_{m \times n}
$$

where, the model consists of $m=18$ alternatives (the number of nested designs considered) and $n=54$ criteria $(18 \times \mathrm{SEA}, 18 \times \mathrm{PCF}$, and $18 \times \mathrm{CFE})$. Accordingly, $x_{i j}$ is the score of the alternative $i$ with respect to the criterion $j$. Following this, the normalisation decision matrix is evaluated as shown in Eq. 6, where $r_{i j}$ is given by Eq. 7:

$$
R=\left(r_{i j}\right)_{m \times n}
$$




$$
r_{i j}=\frac{x_{i j}}{\sqrt{\sum_{i=1}^{m} x_{i j}^{2}}}
$$

Following this, the weighted normalised decision matrix is generated as shown in Eq. 8:

$$
t_{i j}=r_{i j} \times w_{j}
$$

where, $w_{j}$ is the normalised weight represented using Eq. 9 with $W_{j}$ being the original weight given to the indicator. Accordingly, the worst alternative $\left(A_{w}\right)$ and the best alternative $\left(A_{b}\right)$ are represented using Eqs. 10 and 11:

$$
\begin{gathered}
w_{j}=\frac{W_{j}}{\sqrt{\sum_{j=1}^{n} W_{j}}} \\
A_{w}=\left\{\left(\max \left(t_{i j}\right) \forall J^{-}\right), \quad\left(\min \left(t_{i j}\right) \forall J^{+}\right)\right\} \equiv t_{w j} \\
A_{b}=\left\{\left(\min \left(t_{i j}\right) \forall J^{-}\right), \quad\left(\max \left(t_{i j}\right) \forall J^{+}\right)\right\} \equiv t_{b j}
\end{gathered}
$$

where, $J^{+}$and $J^{-}$are criteria associated with positive and negative impact and $d_{i w}$ and $d_{i b}$ are the distance between the target alternative $i$ and the worst and best condition expressed using Eqs. 12 and 13:

$$
d_{i w}=\sqrt{\sum_{j=1}^{n}\left(t_{i j}-t_{w j}\right)^{2}}
$$




$$
d_{i b}=\sqrt{\sum_{j=1}^{n}\left(t_{i j}-t_{b j}\right)^{2}}
$$

Finally, the similarity $\left(S_{i w}\right)$ to the worst condition is calculated using Eq. 14, represented as $0<$ $S_{i w}<1$. If $S_{i w}=1$ the alternative solution has the best condition while the worst condition is obtained when $S_{i w}=0$. The alternatives are then ranked according to the value obtained for $S_{i w}$.

$$
S_{i w}=\frac{d_{i w}}{d_{i w}+d_{i b}}
$$

\section{Results and discussion}

\subsection{Validation of the numerical model}

The validation of the numerical model was carried out by comparing both the force-displacement curve and deformation modes with the experimental tests. To ensure the accuracy of the experimental data, several tests were performed under axial loading condition. Figure 7 shows the results from experimental and numerical. Various deformation stages can be identified in the force-displacement curves as presented in Figure 7 (a). The crush force increases first to a peak value and then drop sharply due to the onset of the first wrinkle in the tube. Following this, the force-displacement response exhibits fluctuation behaviour corresponding to periodic folding, i.e. progressive collapse, of the structures. Such behaviour is a typical crush response for the axially loaded structures [71]. It can be seen that the numerical model can accurately capture the force-displacement data at all the compression stages closely following the experimental data. Figure 7 (b) compares the experimental and numerical deformation mode of the tubes at $60 \%$ of its original length. It is clear that the deformation is primarily through the progressive buckling of the structures and the numerical model is able to effectively capture the progressive failure in comparison to real life.

In summary, the force-displacement curve and deformation mode predicted by the numerical simulations are in good agreement with the experimental results. Consequently, the Finite Element (FE) model established in this study is sufficiently validated and is considered for further analysis of the nested tube designs presented in Figure 2. 


\subsection{Role of nested arrangements in enhancing the crashworthiness behaviour}

In order to show how the nested arrangement can enhance the crashworthiness behaviour, a comparison was made between the responses of tubes when they are loaded separately and also when they are stacked together to create a nested tube system. The nested structure C-C-C, which comprises three components with circular cross sections, was considered as an example to explore the crashworthiness enhancement in the nested tubes. Figure 8 (a) shows the crush response of the nested structure C-C-C along with the force-displacement curves of its components, i.e. inner, middle, and outer tubes, when they are crushed separately. It is worth to mention that the crush responses of the middle and outer tubes were phased along the displacement axis in order to consider the changes in length of the different tubes. The curve with label 'sum' refers to the sum of the crush forces of the individual components. It is evident from Figure 8 that the nested structure exhibits significantly higher EA without increasing PCF. Thus, the shaded area confined between the 'sum' and nested curves indicates the energy absorption enhancement resulting from adopting the nested configuration in the structure C-C-C. This enhancement can be attributed to the interactions between the different components of the nested structure.

The interaction effects can be explained by referring to the deformation mode of the different components in the nested structure. During the progressive collapse of the nested structure, contacts take place between inner and middle tubes, as well as between middle and outer tubes. Once the contacts are established, the external tubes impose circumferential constraints on the internal ones leading to a change in the deformation modes of the latter. Such circumferential resistance offered by the external tubes forces the internal components to deform with smaller wavelengths than those when they deform separately and this leads to an increase in the number of lobes generated during the deformation process of nested tubes and thus enhance the energy absorption capacity of the nested structure.

A further comparison was made between the crashworthiness metrics of the nested structure and its components as shown in Figure 8 (b). It can be seen that nested structure has higher SEA and $\psi$ than the sums of these crashworthiness metrics for the individual tubes. The nested configuration can increase the crashworthiness indicators, i.e. energy absorption per unit mass and the energy absorbing effectiveness factor, by $9 \%$, approximately. 


\subsection{Crashworthiness performance of Haversian inspired nested tubes}

Figure 9 shows the force-displacement curves obtained from the numerical simulations on the axial collapse of nested tubes with different configurations. The nested designs presented in Figure 9 (a), (b), and (c) feature a circular, hexagonal and square outer tube, respectively. From the force-displacement curve, three main stages can be extracted each corresponding to the crushing of the inner (stage 1), middle (stage 2) and outer (stage 3) tubes of the nested system. In stage 1 , the crushing process starts when the upper rigid plate come in touch with the inner tube of the nested system that starts deforming as the rigid plate moves downward. Following this and as the rigid plate continues to crush the nested system, the middle tube starts deforming in stage 2. The process continues in stage 3 where the outer tube engages in the overall deformation. In stages 2 and 3, the axial load rises respectively as a result of the interaction between inner, middle and outer tubes of the nested system. Once the deformation of the outer tube (stage 1) coincided with the middle tube, both the circular (Figure 9 (a)) and square system (Figure 9 (c)) showed growth in load due to interaction effects in stage 2. However, for the hexagonal design, the performance in stage 2 was more or less constant. Although, in stage 3, the interaction effect was observed for all the three groups (Circular, Hexagonal and Square) tested. This shows that all the three tubes in the nested system works collaboratively for a controlled failure through the deformation cycle. For the ribs enhanced nested tubes, their impact forces are generally higher than the standard tubes with the same cross-sectional shape. Consequently, it can be concluded that the nested tubes designs with reinforcement walls can offer superior crush behaviour.

The effectiveness of using internal ribs for enhancing the crashworthiness performance were also reported in previous studies [72]. For example, Annisa et al [72] reported a significant improvement in the energy absorption behaviour of double-walled square columns when internal ribs were introduced to them. Additionally, Zhang et al [73] reported that for a hexagonal bitubal structure, using strong internal ribs are among the preferred design options for achieving best energy absorption characteristics.

The crashworthiness enhancement obtained from using internal ribs in the nested structures is mainly due to two factors. First, the ribs can be viewed as an additional material in the structure which absorbs energy during their plastic deformation. Secondly, the ribs create more 
interactions between the different components of the nested structures and these improved interactions effectively change the folding modes to more stable and favourable ones.

Figure 10 shows the crashworthiness metrics of the nested tubes predicted using the validated finite element model. Evaluating the specific energy absorption as shown in Figure 10 (a), it is evident that the nested tubes feature reinforcements, denoted by $r$ symbol, absorb more energy than the standard designs. Although the ribs might increase the overall mass of the nested structure, the energy absorption enhancement obtained from introducing the ribs outperforms the mass increase and leads to overall improvement in the crashworthiness metrics. For example, the mass of $\mathrm{C}-\mathrm{C}-\mathrm{Cr}$ structure is $10 \%$ higher than the mass of its counterpart design without ribs, i.e. C-C-C structure. However, the structure C-C-Cr absorbs approximately $24 \%$ more energy than the $\mathrm{C}-\mathrm{C}-\mathrm{C}$ structure and this yields an overall improvement in SEA response equals to $13 \%$. The best performance with respect to SEA was exhibited by H-C-Sr (Category: Hexagonal) outperforming S-S-S (Category: Square) by approximately 30\%. In addition to the role of the ribs, the superior SEA response offered by $\mathrm{H}-\mathrm{C}-\mathrm{Sr}$ structure might be due to better interaction effects between its components caused by its geometrical shape. By a close inspection of $\mathrm{H}-\mathrm{C}-\mathrm{Sr}$ cross section, one can easily see that the gap size between the inner and middle tubes; and between middle and outer tubes is not consistent along the circumferential of these tubes. The gap becomes smaller in some regions of the structure and this smaller gap allows for greater contact area between the tubes of structure during the deformation process. Comparing the SEA of the designs without a reinforcement wall, the highest performance was exhibited by C-C-C absorbing $20.23 \mathrm{~kJ} / \mathrm{kG}$ which accounts for an improvement of $13 \%$ over S-S-S tube. For the reinforced designs, the worst performance was exhibited by S-S-Sr which absorbs approximately $10.4 \%$ less energy than the best-reinforced design H-C-Sr.

Examining the PCF response as presented in Figure 10 (b), it can be seen that the PCF values of all the nested tubes are comparable within a range of 21 to $24.2 \mathrm{kN}$, the limits represented by designs H-S-C and C-H-S, respectively. Also, the nested structures with internal ribs exhibit almost identical PCF values to their counterparts without ribs. This is mainly because the onset of failure starts in stage 1 where the resistance is primarily offered by the inner tube alone. However, in stages 2 and 3, the crushing force increased due to the added resistance offered by the deformation of the middle and outer tubes. For designs categorised under circular outer tube, 
the lowest PCF was exhibited by C-C-C, followed by $\mathrm{H}-\mathrm{S}-\mathrm{C}$ and $\mathrm{S}-\mathrm{H}-\mathrm{C}$ for hexagonal and square categories, respectively.

For a well-designed energy absorbing system a balance between energy absorption and crush force is often desired [74,75]. This is primarily because a high SEA and low PCF are often considered the best features of an efficient energy absorption system. Consequently, the CFE is often employed as an indicator to characterise the performance of energy absorbers. The CFE combines both SEA and PCF parameters as a ratio allowing to identify the best performing designs. Comparing CFE as shown in Figure 10 (c), the nested tube designs that feature an outer square cross-section (Category: Square) performed inferior to the designs that feature a hexagonal and circular outer tube. The highest crush force efficiency was exhibited by C-H-Sr which has a $20 \%$ improvement in comparison to the worst performing design S-S-S. Overall, the designs that feature a reinforcement wall were found to outperform the simple nested design. This is because of the added interaction effects offered by the reinforcement wall allowing all the designs to work together as a single system.

Figure 11 presents the deformed shapes for all the nested tube designs considered. It can be seen that under perfectly axial loading, all the nested designs folded progressively and none of them experience the global bending deformation mode. However, the designs that feature a reinforcement wall have a more desirable symmetrical deformation mode with a higher number of folds than those observed in designs without reinforcement. The ribs in a nested structure play a stiffener's role which impose more resistance towards buckling and alter the deformation mode of the components in the nested structure. Analysing the deformation mode associated with H-S$\mathrm{C}$ and S-H-C tubes, it can be seen that the deformation mode is unsymmetrical and the interaction effects offered by the nesting is minimal.

\subsection{Identifying the best design}

TOPSIS is employed to determine the best energy absorber among those investigated in this study. Using the responses of SEA, PCF, and CFE as shown in Table 2, the designs are ranked from 1 and 18, where 1 is the best and 18 is the worst energy absorber. The ranking is based on the value of $S_{i w}$ calculated based on Eq.14. 
The ranking metrics identifies S-H-Cr as the best design (Rank 1) that feature the right balance between low PCF, high CFE, and high SEA in comparison to other designs. C-S-H was identified as the worst design at a rank of 18 based on the $S_{i w}$ value as it neither had high SEA value nor low PCF. Based on the $S_{i w}$ value, the performance of C-S-H was $72.5 \%$ away from the ideal identified as Rank 1. Furthermore, comparing the results in Table 3, it can be seen that all of the top ranking designs feature a reinforcement wall and this indicates that ribs-enhanced tubes are more suitable for the crashworthiness applications.

\section{Conclusion}

Crashworthiness and energy absorption characteristics of bio-inspired nested structures with various cross sections were studied. Three groups of designs (circular, hexagonal, and square) each featuring an equal number of reinforced and non-reinforced nested designs were analysed. Comparison between experimental and numerical data showed good agreement validating the modelling methodology. The force-displacement and deformation modes of the nested tubes showed three distinctive stages each characterised by deformation of the outer, middle and inner tubes. This resulted in increasing impact due to the interaction effects between the different components of the nested structures at stages 2 and 3. Overall, the nested tubes with reinforcement walls outperformed other designs offering higher SEA. After studying PCF, SEA and CFE, the designs were ranked using a multi-criteria decision-making method (TOPSIS). The results showed that nested tube with reinforcement walls (S-H-Cr) has the highest score and the best crashworthiness performance tube with a lower impact force and higher specific energy absorption. The design methodology presented in this paper may lead to the design of new bionic structures with excellent energy absorption performance.

\section{References}

[1] W. (William) Johnson, A.G. Mamalis, Crashworthiness of vehicles : an introduction to aspects of collision of motor cars, ships, aircraft and railway coaches, Mechanical Engineering Publications, 1978.

[2] W. Johnson, S.R. Reid, METALLIC ENERGY DISSIPATING SYSTEMS., Appl. Mech. Rev. 31 (1978) 277-288. 
[3] C.R. Calladine, Analysis of Large Plastic Deformations in Shell Structures, in: Inelast. Behav. Plates Shells, Springer Berlin Heidelberg, Berlin, Heidelberg, 1986: pp. 69-101. doi:10.1007/978-3-642-82776-1_4.

[4] F.A. Leckie, R.K. Penny, Plastic instability of a spherical shell, Eng. Plast. (1968) 401411.

[5] N.. Gupta, G.. E. Prasad, S.. Gupta, Axial compression of metallic spherical shells between rigid plates, Thin-Walled Struct. 34 (n.d.) 21-41.

[6] A. Baroutaji, E. Morris, A.G. Olabi, Quasi-static response and multi-objective crashworthiness optimization of oblong tube under lateral loading, Thin-Walled Struct. 82 (2014) 262-277. doi:10.1016/j.tws.2014.03.012.

[7] B.F. Xing, D.Y. Hu, Y.X. Sun, J.L. Yang, T.X. Yu, Effects of hinges and deployment angle on the energy absorption characteristics of a single cell in a deployable energy absorber, Thin-Walled Struct. 94 (2015) 107-119. doi:10.1016/j.tws.2015.04.015.

[8] X.W. Zhang, H. Su, T.X. Yu, Energy absorption of an axially crushed square tube with a buckling initiator, Int. J. Impact Eng. 36 (2009) 402-417. doi:10.1016/j.ijimpeng.2008.02.002.

[9] C. Reuter, K.-H. Sauerland, T. Tröster, Experimental and numerical crushing analysis of circular CFRP tubes under axial impact loading, Compos. Struct. 174 (2017) 33-44. doi:10.1016/j.compstruct.2017.04.052.

[10] A. Baroutaji, M.D. Gilchrist, D. Smyth, A.G. Olabi, Crush analysis and multi-objective optimization design for circular tube under quasi-static lateral loading, Thin-Walled Struct. 86 (2015) 121-131. doi:10.1016/j.tws.2014.08.018.

[11] S. Pirmohammad, H. Nikkhah, Crashworthiness investigation of bitubal columns reinforced with several inside ribs under axial and oblique impact loads, Proc. Inst. Mech. Eng. Part D J. Automob. Eng. 232 (2018) 367-383. doi:10.1177/0954407017702986.

[12] M. Ali, E. Ohioma, F. Kraft, K. Alam, Theoretical, numerical, and experimental study of dynamic axial crushing of thin walled pentagon and cross-shape tubes, Thin-Walled 
Struct. 94 (2015) 253-272. doi:10.1016/j.tws.2015.04.007.

[13] X. Song, G. Sun, G. Li, W. Gao, Q. Li, Crashworthiness optimization of foam-filled tapered thin-walled structure using multiple surrogate models, Struct. Multidiscip. Optim. 47 (2012) 221-231. doi:10.1007/s00158-012-0820-6.

[14] G. Li, F. Xu, G. Sun, Q. Li, Crashworthiness study on functionally graded thin-walled structures, Int. J. Crashworthiness. 20 (2015) 280-300.

doi:10.1080/13588265.2015.1010396.

[15] A. Baroutaji, M.D. Gilchrist, D. Smyth, A.G. Olabi, Analysis and optimization of sandwich tubes energy absorbers under lateral loading, Int. J. Impact Eng. 82 (2015) 7488. doi:10.1016/j.ijimpeng.2015.01.005.

[16] A. Baroutaji, A.G. Olabi, Lateral collapse of short-length sandwich tubes compressed by different indenters and exposed to external constraints, Materwiss. Werksttech. 45 (2014) n/a-n/a. doi:10.1002/mawe.201400236.

[17] I. Ivañez, L.M. Fernandez-Cañadas, S. Sanchez-Saez, Compressive deformation and energy-absorption capability of aluminium honeycomb core, Compos. Struct. 174 (2017) 123-133. doi:10.1016/J.COMPSTRUCT.2017.04.056.

[18] Z. Wang, J. Liu, D. Hui, Mechanical behaviors of inclined cell honeycomb structure subjected to compression, Compos. Part B Eng. 110 (2017) 307-314. doi:10.1016/j.compositesb.2016.10.062.

[19] J. Fang, Y. Gao, G. Sun, N. Qiu, Q. Li, On design of multi-cell tubes under axial and oblique impact loads, Thin-Walled Struct. 95 (2015) 115-126. doi:10.1016/j.tws.2015.07.002.

[20] A. Baroutaji, A. Arjunan, A. Niknejad, T. Tran, A.-G. Olabi, Application of Cellular Material in Crashworthiness Applications: An Overview, Ref. Modul. Mater. Sci. Mater. Eng. (2019). doi:10.1016/B978-0-12-803581-8.09268-7.

[21] J. Song, Y. Chen, G. Lu, Light-weight thin-walled structures with patterned windows under axial crushing, Int. J. Mech. Sci. 66 (2013) 239-248. 
doi:10.1016/j.ijmecsci.2012.11.014.

[22] J. Song, Numerical simulation on windowed tubes subjected to oblique impact loading and a new method for the design of obliquely loaded tubes, Int. J. Impact Eng. 54 (2013) 192-205. doi:10.1016/J.JJIMPENG.2012.11.005.

[23] H. Nikkhah, F. Guo, Y. Chew, J. Bai, J. Song, P. Wang, The effect of different shapes of holes on the crushing characteristics of aluminum square windowed tubes under dynamic axial loading, Thin-Walled Struct. 119 (2017) 412-420. doi:10.1016/j.tws.2017.06.036.

[24] H. Nikkhah, A. Baroutaji, A.G. Olabi, Crashworthiness design and optimisation of windowed tubes under axial impact loading, Thin-Walled Struct. 142 (2019) 132-148. doi:10.1016/J.TWS.2019.04.052.

[25] N. Qiu, Y. Gao, J. Fang, Z. Feng, G. Sun, Q. Li, Crashworthiness analysis and design of multi-cell hexagonal columns under multiple loading cases, Finite Elem. Anal. Des. 104 (2015) 89-101. doi:10.1016/j.finel.2015.06.004.

[26] G. Sun, T. Liu, J. Fang, G.P. Steven, Q. Li, Configurational optimization of multi-cell topologies for multiple oblique loads, Struct. Multidiscip. Optim. 57 (2018) 469-488. doi:10.1007/s00158-017-1839-5.

[27] Z. Wang, J. Liu, S. Yao, On folding mechanics of multi-cell thin-walled square tubes, Compos. Part B Eng. 132 (2018) 17-27. doi:10.1016/J.COMPOSITESB.2017.07.036.

[28] T. Tran, D. Le, A. Baroutaji, Theoretical and numerical crush analysis of multi-stage nested aluminium alloy tubular structures under axial impact loading, Eng. Struct. 182 (2019) 39-50. doi:10.1016/j.engstruct.2018.12.072.

[29] T. Tran, A. Baroutaji, Crashworthiness optimal design of multi-cell triangular tubes under axial and oblique impact loading, Eng. Fail. Anal. 93 (2018) 241-256.

doi:10.1016/J.ENGFAILANAL.2018.07.003.

[30] S. Ramakrishna, H. Hamada, Energy Absorption Characteristics of Crash Worthy Structural Composite Materials, Key Eng. Mater. 141-143 (1998) 585-622. doi:10.4028/www.scientific.net/KEM.141-143.585. 
[31] K.C. Shin, J.J. Lee, K.H. Kim, M.C. Song, J.S. Huh, Axial crush and bending collapse of an aluminum/GFRP hybrid square tube and its energy absorption capability, Compos. Struct. 57 (2002) 279-287. doi:10.1016/S0263-8223(02)00094-6.

[32] E.H. Hanefi, T. Wierzbicki, Axial resistance and energy absorption of externally reinforced metal tubes, Compos. Part B Eng. 27 (1996) 387-394. doi:10.1016/13598368(96)00002-9.

[33] A.G. Mamalis, M. Robinson, D.E. Manolakos, G.A. Demosthenous, M.B. Ioannidis, J. Carruthers, Crashworthy capability of composite material structures, Compos. Struct. 37 (1997) 109-134. doi:10.1016/S0263-8223(97)80005-0.

[34] A.G. Olabi, E. Morris, M.S.J. Hashmi, Metallic tube type energy absorbers: A synopsis, Thin-Walled Struct. 45 (2007) 706-726. doi:10.1016/j.tws.2007.05.003.

[35] A. Baroutaji, M. Sajjia, A.-G. Olabi, On the crashworthiness performance of thin-walled energy absorbers: Recent advances and future developments, Thin-Walled Struct. 118 (2017) 137-163. doi:10.1016/j.tws.2017.05.018.

[36] A. Alavi Nia, S. Chahardoli, Optimizing the layout of nested three-tube structures in quasi-static axial collapse, Thin-Walled Struct. 107 (2016) 169-181. doi:10.1016/J.TWS.2016.06.010.

[37] A.A. Nia, S. Chahardoli, Mechanical behavior of nested multi-tubular structures under quasi-static axial load, Thin-Walled Struct. 106 (2016) 376-389. doi:10.1016/J.TWS.2016.05.012.

[38] F. Usta, H.S. Türkmen, Experimental and numerical investigation of impact behavior of nested tubes with and without honeycomb filler, Thin-Walled Struct. 143 (2019). doi:10.1016/j.tws.2019.106256.

[39] A. Baroutaji, M.D. Gilchrist, A.G. Olabi, Quasi-static, impact and energy absorption of internally nested tubes subjected to lateral loading, Thin-Walled Struct. 98 (2016) 337350. doi:10.1016/j.tws.2015.10.001.

[40] A.G. Olabi, E. Morris, M.S.J. Hashmi, M.D. Gilchrist, Optimised design of nested oblong 
tube energy absorbers under lateral impact loading, Int. J. Impact Eng. 35 (2008) 10-26. doi:10.1016/j.ijimpeng.2006.11.007.

[41] H. Wang, J. Yang, H. Liu, Y. Sun, T.X.X. Yu, Internally nested circular tube system subjected to lateral impact loading, Thin-Walled Struct. 91 (2015) 72-81. doi:10.1016/j.tws.2015.02.014.

[42] T. Tran, A study on nested two-tube structures subjected to lateral crushing, Thin-Walled Struct. 129 (2018) 418-428. doi:10.1016/J.TWS.2018.04.022.

[43] S. Chahardoli, A. Alavi Nia, M. Asadi, A parametric study of the mechanical behavior of nested multi tube structures under quasi-static loading, Arch. Civ. Mech. Eng. 19 (2019) 943-957. doi:10.1016/j.acme.2019.03.006.

[44] J. Hu, G. Lu, H. Yang, T.X. Yu, J. Xu, Dynamic response of internally nested hemispherical shell system to impact loading, Thin-Walled Struct. 120 (2017) 29-37. doi:10.1016/j.tws.2017.08.009.

[45] F. Usta, Z. Eren, H. Kurtaran, H.S. Türkmen, Z. Kazanc1, Z. Mecitoglu, Crashworthiness Optimization of Nested and Concentric Circular Tubes Using Response Surface Methodology and Genetic Algorithm, Lat. Am. J. Solids Struct. 15 (2018). doi:10.1590/1679-78254385.

[46] J. Li, G. Gao, W. Guan, S. Wang, Y. Yu, Experimental and numerical investigations on the energy absorption of shrink circular tube under quasi-static loading, Int. J. Mech. Sci. 137 (2018) 284-294. doi:https://doi.org/10.1016/j.ijmecsci.2018.01.019.

[47] N.S. Ha, G. Lu, X. Xiang, High energy absorption efficiency of thin-walled conical corrugation tubes mimicking coconut tree configuration, Int. J. Mech. Sci. 148 (2018) 409-421. doi:https://doi.org/10.1016/j.ijmecsci.2018.08.041.

[48] Z. Xin, Y. Duan, J. Zhou, H. Xiao, Effect of tailored plies on the energy absorption capability of square CFRP tubes with discontinuous fibers, Compos. Struct. 209 (2019) 150-159. doi:https://doi.org/10.1016/j.compstruct.2018.09.010.

[49] H.S. Googarchin, M. Pasandidehpoor, A. Mahmoodi, M.H. Shojaeefard, Energy 
absorption analysis for tapered multi-cell tubes improved by foams: Theoretical development and numerical simulation, Compos. Struct. 207 (2019) 213-222. doi:https://doi.org/10.1016/j.compstruct.2018.09.032.

[50] H. Mozafari, S. Lin, G.C.P. Tsui, L. Gu, Controllable energy absorption of double sided corrugated tubes under axial crushing, Compos. Part B Eng. 134 (2018) 9-17. doi:https://doi.org/10.1016/j.compositesb.2017.09.042.

[51] A. Niknejad, P.H.H. Orojloo, A novel nested system of tubes with special cross-section as the energy absorber, Thin-Walled Struct. 100 (2016) 113-123. doi:10.1016/j.tws.2015.12.009.

[52] B. Xu, C. Wang, W. Xu, An efficient energy absorber based on fourfold-tube nested circular tube system, Thin-Walled Struct. 137 (2019) 143-150. doi:https://doi.org/10.1016/j.tws.2019.01.026.

[53] M.A. Meyers, P.-Y. Chen, A.Y.-M. Lin, Y. Seki, Biological materials: Structure and mechanical properties, Prog. Mater. Sci. 53 (2008) 1-206. doi:10.1016/j.pmatsci.2007.05.002.

[54] G.W. Kooistra, V. Deshpande, H.N.G. Wadley, Hierarchical corrugated core sandwich panel concepts, J. Appl. Mech. Trans. ASME. 74 (2007) 259-268. doi:10.1115/1.2198243.

[55] D. Hu, Y. Wang, B. Song, L. Dang, Z. Zhang, Energy-absorption characteristics of a bionic honeycomb tubular nested structure inspired by bamboo under axial crushing, Compos. Part B Eng. 162 (2019) 21-32. doi:10.1016/J.COMPOSITESB.2018.10.095.

[56] Z. Zhang, Y.-W. Zhang, H. Gao, On optimal hierarchy of load-bearing biological materials, Proc. R. Soc. B Biol. Sci. 278 (2011) 519-525. doi:10.1098/rspb.2010.1093.

[57] X. Xu, Y. Zhang, J. Wang, F. Jiang, C.H. Wang, Crashworthiness design of novel hierarchical hexagonal columns, Compos. Struct. 194 (2018) 36-48. doi:10.1016/j.compstruct.2018.03.099.

[58] M. Langseth, O.S. Hopperstad, T. Berstad, Crashworthiness of aluminum extrusions: 
Validation of numerical simulation, effect of mass ratio and impact velocity, Int. J. Impact Eng. 22 (1999) 829-854. doi:10.1016/S0734-743X(98)00070-0.

[59] A. Reyes, M. Langseth, O.S. Hopperstad, Crashworthiness of aluminum extrusions subjected to oblique loading: experiments and numerical analyses, Int. J. Mech. Sci. 44 (2002) 1965-1984. doi:10.1016/S0020-7403(02)00050-4.

[60] M. Langseth, O.S. Hopperstad, Static and dynamic axial crushing of square thin-walled aluminium extrusions, Int. J. Impact Eng. 18 (1996) 949-968. doi:10.1016/S0734$743 X(96) 00025-5$.

[61] Ø. Jensen, Behaviour of Aluminium Extrusions Subjected to Axial Loading, (2005).

[62] A.G. Hanssen, M. Langseth, O.S. Hopperstad, Static and dynamic crushing of square aluminium extrusions with aluminium foam filler, Int. J. Impact Eng. 24 (2000) 347-383. doi:10.1016/S0734-743X(99)00169-4.

[63] M. Costas, D. Morin, M. Langseth, L. Romera, J. D??az, J. Díaz, Axial crushing of aluminum extrusions filled with PET foam and GFRP. An experimental investigation, Thin-Walled Struct. 99 (2016) 45-57. doi:10.1016/j.tws.2015.11.003.

[64] S. Yi Jin, W. Altenhof, T. Kapoor, An experimental investigation into the cutting deformation mode of AA6061-T6 round extrusions, Thin-Walled Struct. 44 (2006) 773786. doi:10.1016/j.tws.2006.05.009.

[65] A. Reyes, O.S. Hopperstad, M. Langseth, Aluminum foam-filled extrusions subjected to oblique loading: experimental and numerical study, Int. J. Solids Struct. 41 (2004) 16451675. doi:10.1016/j.ijsolstr.2003.09.053.

[66] X. Yu, X. Qiu, T.X. Yu, Analysis of the free external inversion of circular tubes based on deformation theory, Int. J. Mech. Sci. 100 (2015) 262-268. doi:10.1016/j.ijmecsci.2015.06.017.

[67] J.J. Carruthers, A.P. Kettle, A.M. Robinson, Energy Absorption Capability and Crashworthiness of Composite Material Structures: A Review, Appl. Mech. Rev. 51 (1998) 635. doi:10.1115/1.3100758. 
[68] N. Jones, Energy-absorbing effectiveness factor, Int. J. Impact Eng. 37 (2010) 754-765. doi:10.1016/j.ijimpeng.2009.01.008.

[69] C.-L. Hwang, K. Yoon, Methods for multiple attribute decision making, Mult. Attrib. Decis. Mak. (1981) 58-191.

[70] S. Pirmohammad, S. Esmaeili Marzdashti, Crashworthiness optimization of combined straight-tapered tubes using genetic algorithm and neural networks, Thin-Walled Struct. 127 (2018) 318-332. doi:10.1016/J.TWS.2018.01.022.

[71] N. Jones, Structural Impact, 2nd edition, Cambridge University Press, 2012. https://books.google.com/books?id=AkGnbX4kIsEC\&pgis=1 (accessed January 20, 2016).

[72] A. Jusuf, T. Dirgantara, L. Gunawan, I.S. Putra, Crashworthiness analysis of multi-cell prismatic structures, Int. J. Impact Eng. 78 (2015) 34-50. doi:10.1016/j.ijimpeng.2014.11.011.

[73] X. Zhang, G. Cheng, B. Wang, H. Zhang, Optimum design for energy absorption of bitubal hexagonal columns with honeycomb core, Int. J. Crashworthiness. 13 (2008) 99107. doi:10.1080/13588260701731732.

[74] K. Yang, Y. Chen, S. Liu, C. Qiao, J. Yang, Internally nested self-locked tube system for energy absorption, Thin-Walled Struct. 119 (2017) 371-384. doi:10.1016/j.tws.2017.06.014.

[75] Y. Xiang, T. Yu, L. Yang, Comparative analysis of energy absorption capacity of polygonal tubes, multi-cell tubes and honeycombs by utilizing key performance indicators, Mater. Des. 89 (2016) 689-696. doi:10.1016/j.matdes.2015.10.004. 
Table 1. Mechanical properties of extruded AL6060-T4

\begin{tabular}{cccc}
\hline & Extrusion direction & Transverse direction & Difference (\%) \\
\hline $\mathrm{E}(\mathrm{GPa})$ & 69.8 & 65 & 6.87 \\
$\sigma_{y}(\mathrm{MPa})$ & 89.860 & 91.230 & 1.52 \\
$\sigma_{u}(\mathrm{MPa})$ & 145.153 & 136.66 & 5.852 \\
$\varepsilon_{\max }(\%)$ & 20.305 & 19.966 & 1.667
\end{tabular}

Table 2. PCF, SEA and CFE used for the TOPSIS analysis.

\begin{tabular}{ccccc|ccccc}
\hline Tube & $\begin{array}{c}\text { Mass } \\
(\mathbf{k g})\end{array}$ & $\begin{array}{c}\text { PCF } \\
(\mathbf{k N})\end{array}$ & $\begin{array}{c}\text { SEA } \\
(\mathbf{k J} / \mathbf{k G})\end{array}$ & $\begin{array}{c}\text { CFE } \\
(\mathbf{\%})\end{array}$ & Tube & $\begin{array}{c}\text { Mass } \\
(\mathbf{k g})\end{array}$ & $\begin{array}{c}\text { PCF } \\
(\mathbf{k N})\end{array}$ & $\begin{array}{c}\text { SEA } \\
(\mathbf{k J} / \mathbf{k G})\end{array}$ & $\begin{array}{c}\text { CFE } \\
(\mathbf{\%})\end{array}$ \\
\hline C-C-C & 0.169 & 21.12 & 20.23 & 0.447 & H-C-Sr & 0.193 & 24.11 & 24.53 & 0.498 \\
C-C-Cr & 0.186 & 21.28 & 22.87 & 0.491 & H-S-C & 0.169 & 21.06 & 19.09 & 0.487 \\
C-H-S & 0.169 & 24.24 & 19.04 & 0.473 & H-S-Cr & 0.19 & 21.51 & 23.65 & 0.48 \\
C-H-Sr & 0.193 & 24.2 & 24.02 & 0.525 & S-S-S & 0.169 & 24.21 & 17.76 & 0.417 \\
C-S-H & 0.169 & 22.53 & 18.55 & 0.508 & S-S-Sr & 0.195 & 24.18 & 22.12 & 0.486 \\
C-S-Hr & 0.188 & 22.34 & 22.23 & 0.458 & S-C-H & 0.169 & 22.53 & 18.87 & 0.474 \\
H-H-H & 0.169 & 22.53 & 19.57 & 0.476 & S-C-Hr & 0.186 & 22.24 & 23.11 & 0.464 \\
H-H-Hr & 0.189 & 22.25 & 23.27 & 0.501 & S-H-C & 0.169 & 21.06 & 18.58 & 0.475 \\
H-C-S & 0.169 & 24.18 & 18.56 & 0.458 & S-H-Cr & 0.187 & 21.37 & 23.1 & 0.454 \\
\hline
\end{tabular}

Table 3. Ranking of the crashworthiness performance of nested tube designs using TOPSIS

\begin{tabular}{lccccccccc}
\hline & Circle & \multicolumn{4}{c}{ Hexagonal } & \multicolumn{3}{c}{ Square } & \multirow{2}{*}{ Reinforcement } \\
Design & Score & Rank & Design & Score & Rank & Design & Score & Rank & \\
\hline C-C-C & 0.0616 & $\mathbf{8}$ & H-H-H & 0.0414 & $\mathbf{1 4}$ & S-S-S & 0.0452 & $\mathbf{1 1}$ & No \\
C-C-Cr & 0.0715 & $\mathbf{5}$ & H-H-Hr & 0.0678 & $\mathbf{7}$ & S-S-Sr & 0.0562 & $\mathbf{1 0}$ & Yes \\
C-H-S & 0.0322 & $\mathbf{1 6}$ & H-C-S & 0.0267 & $\mathbf{1 7}$ & S-C-H & 0.0366 & $\mathbf{1 5}$ & No \\
C-H-Sr & 0.0607 & $\mathbf{9}$ & H-C-Sr & 0.0692 & $\mathbf{6}$ & S-C-Hr & 0.0800 & $\mathbf{3}$ & Yes \\
C-S-H & 0.0239 & $\mathbf{1 8}$ & H-S-C & 0.0426 & $\mathbf{1 2}$ & S-H-C & 0.0425 & $\mathbf{1 3}$ & No \\
C-S-Hr & 0.0738 & $\mathbf{4}$ & H-S-Cr & 0.0801 & $\mathbf{2}$ & S-H-Cr & 0.0869 & $\mathbf{1}$ & Yes \\
\hline
\end{tabular}




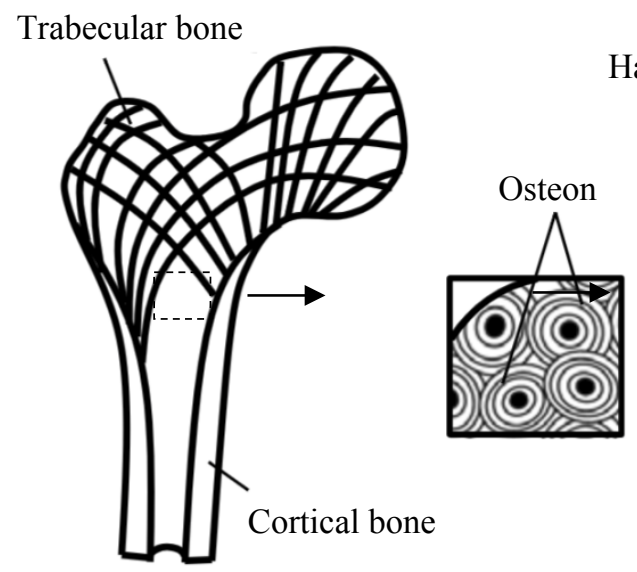

(a)

(b)

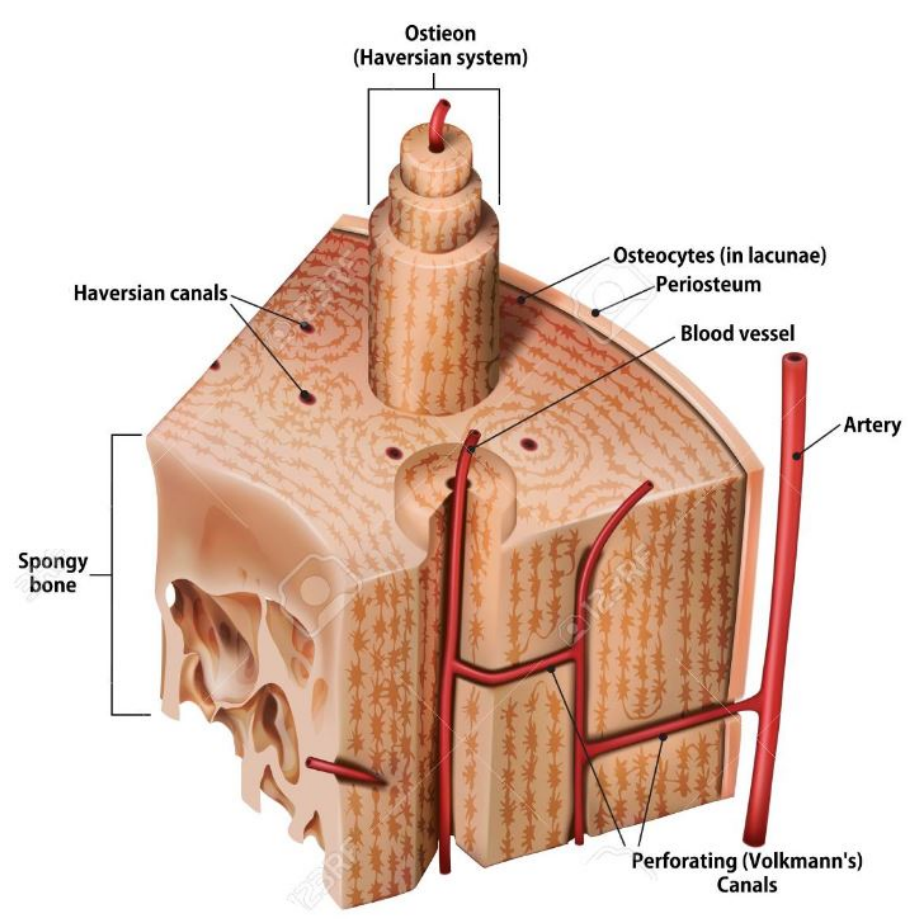

(d)

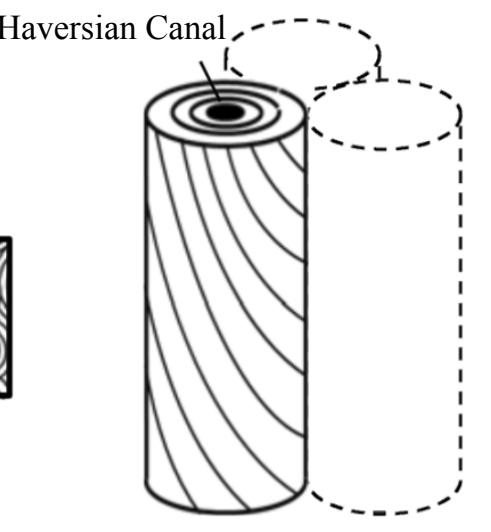

(c) 


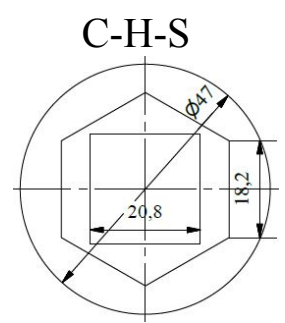

$\mathrm{H}-\mathrm{C}-\mathrm{S}$

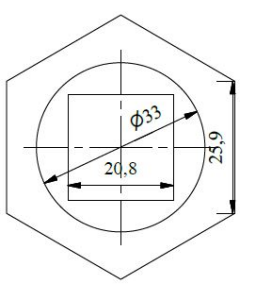

S-C-H

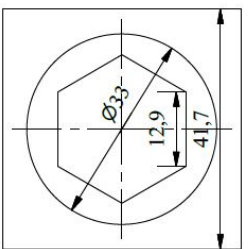

,

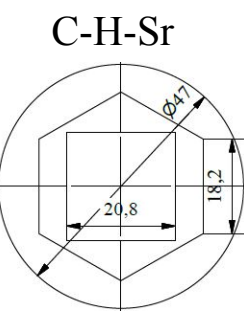

$\mathrm{H}-\mathrm{C}-\mathrm{Sr}$
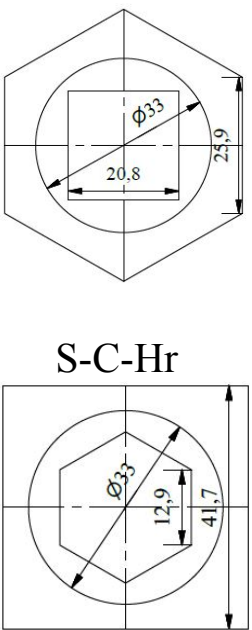

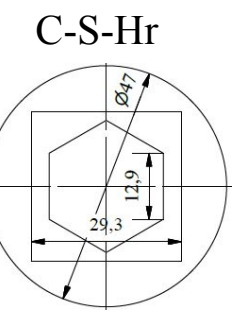

(a)

H-S-C

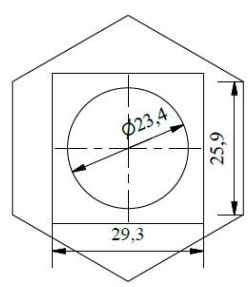

(b)
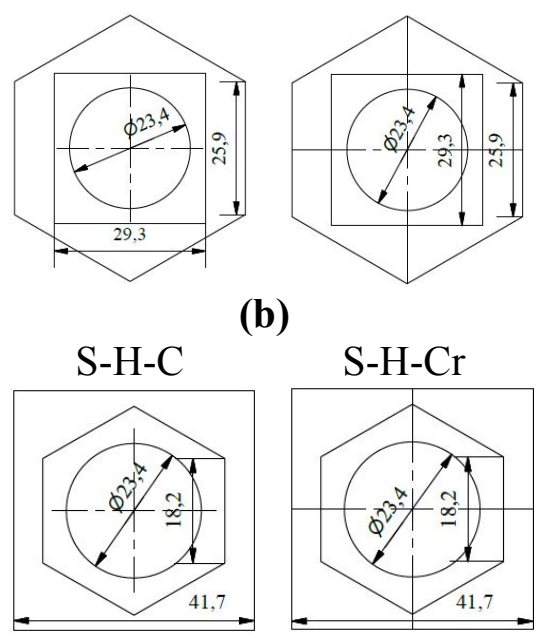

C-C-C

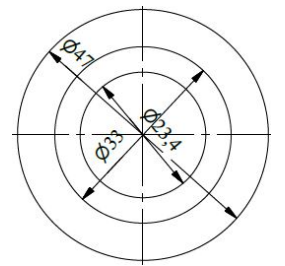

$\mathrm{H}-\mathrm{H}-\mathrm{H}$

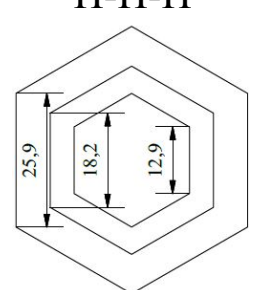

$\mathrm{H}-\mathrm{H}-\mathrm{Hr}$
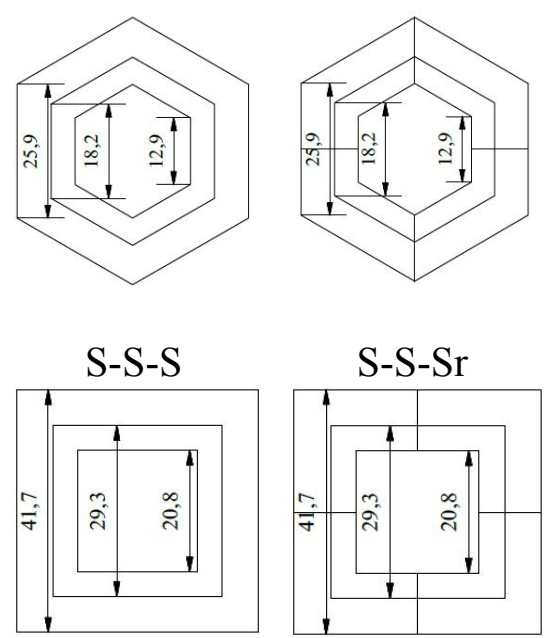

(c)

Figure 2: Design specifications for the nested columns classified based on their global shape (a) Circular outer ring, (b) Hexagonal outer ring, (c) Square outer ring. (The suffix $r$ refers to tubes with reinforcement inside walls and dimension in $\mathrm{mm}$ ) 

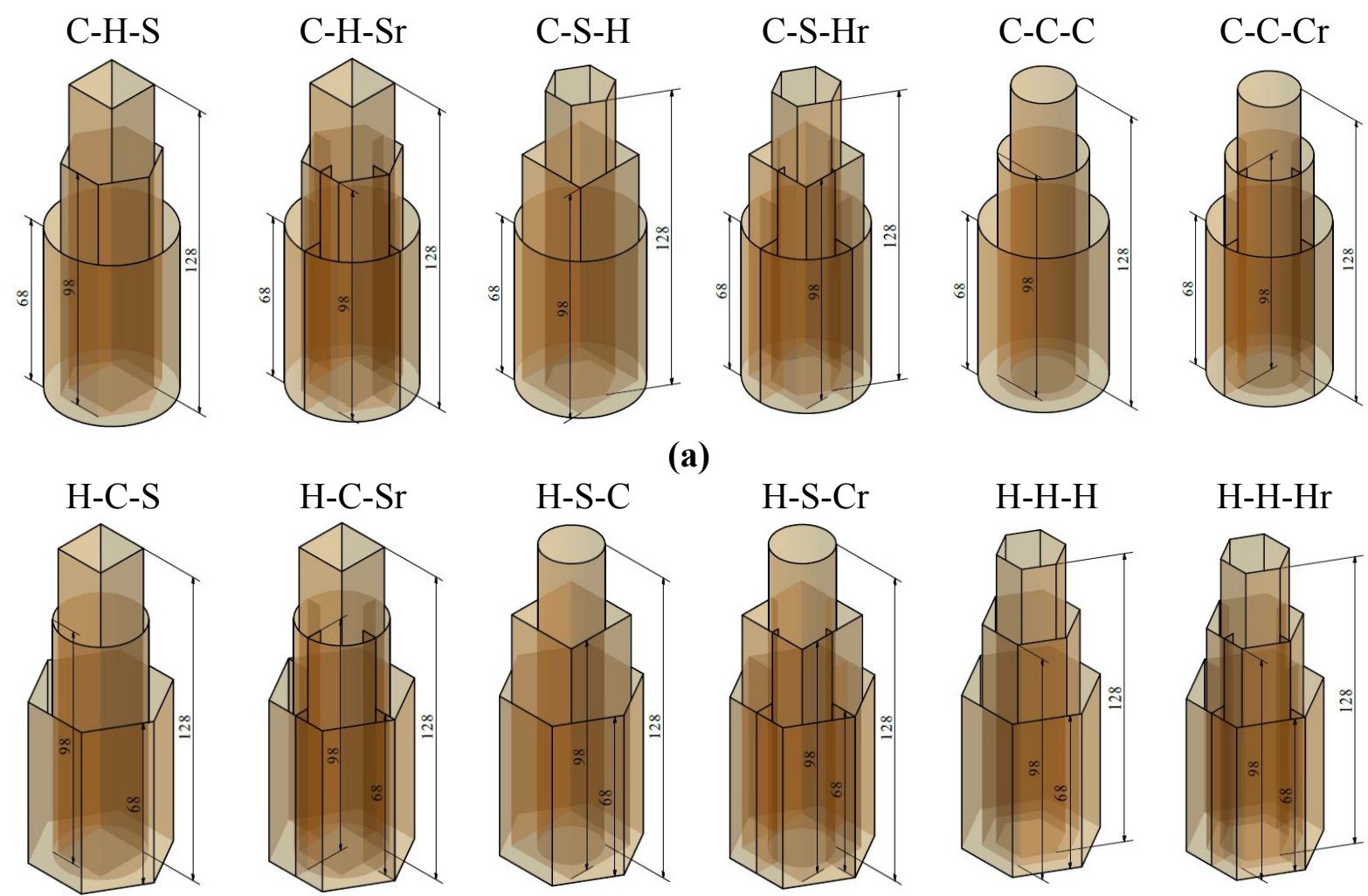

$\mathrm{H}-\mathrm{H}-\mathrm{Hr}$
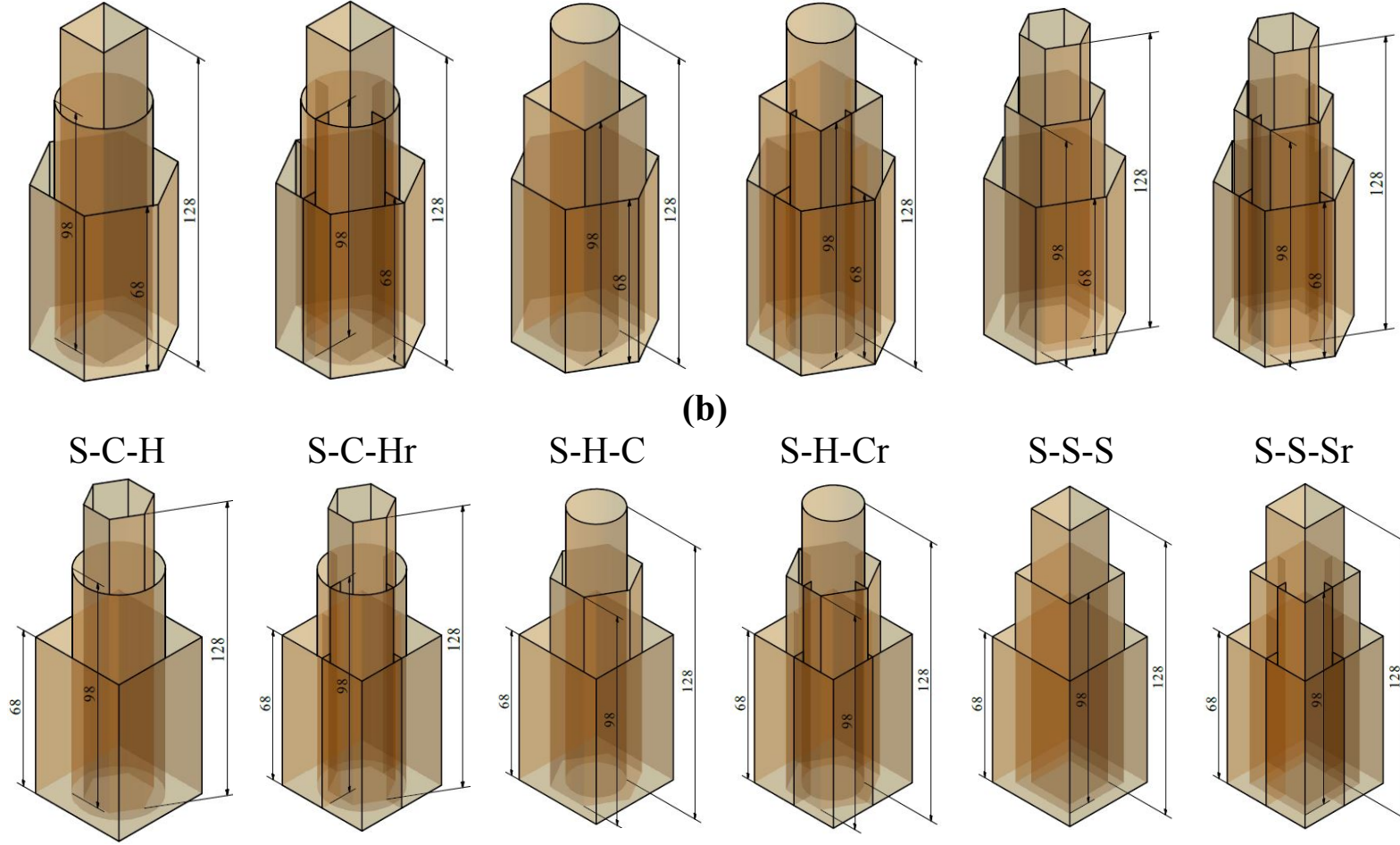

(c)

Figure 3: Length and arrangement of the nested tube considered for controlled failure, where

(a) Circular (C), (b) Hexagonal (H), (c) Square (S) (dimension in mm) 


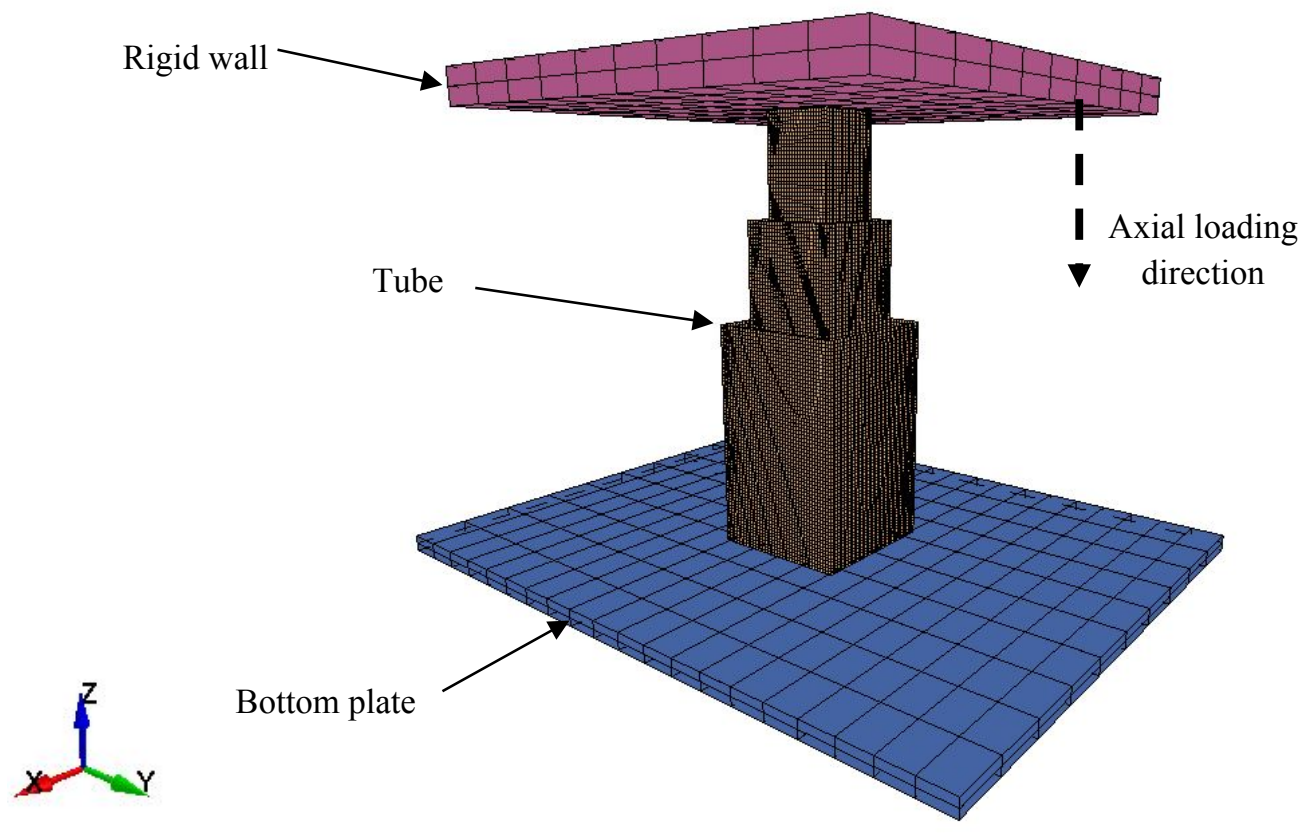

Figure 4: Boundary conditions and mesh resolution of the finite element model. 

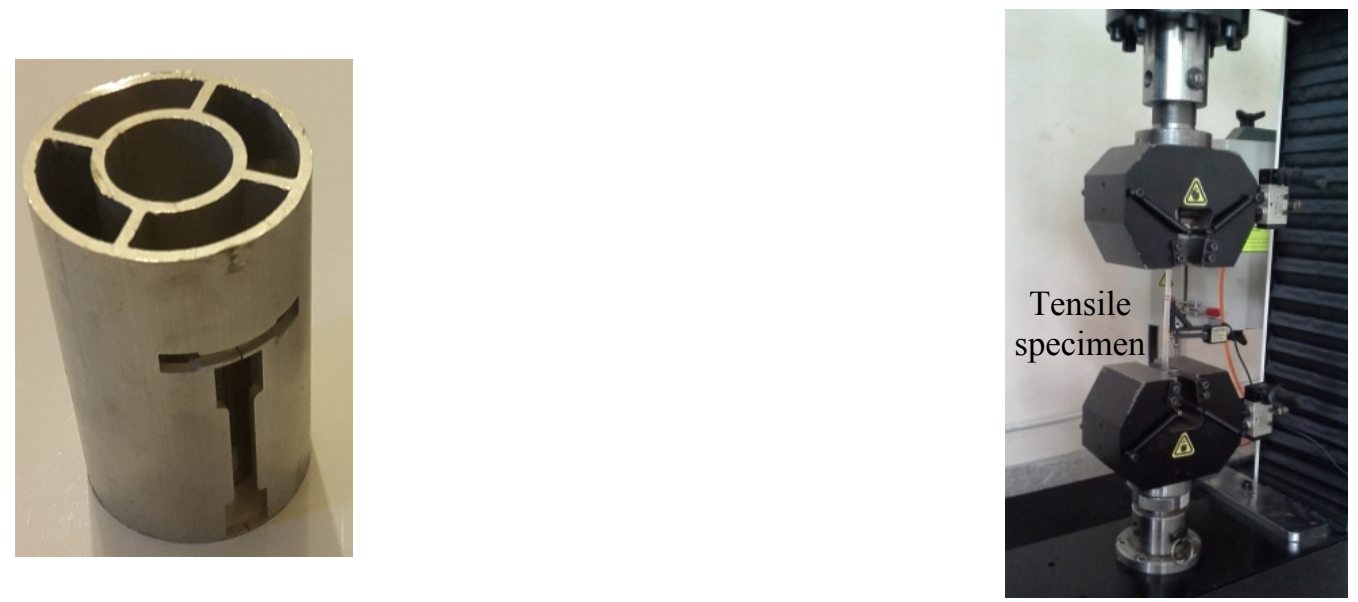

(a)

(b)

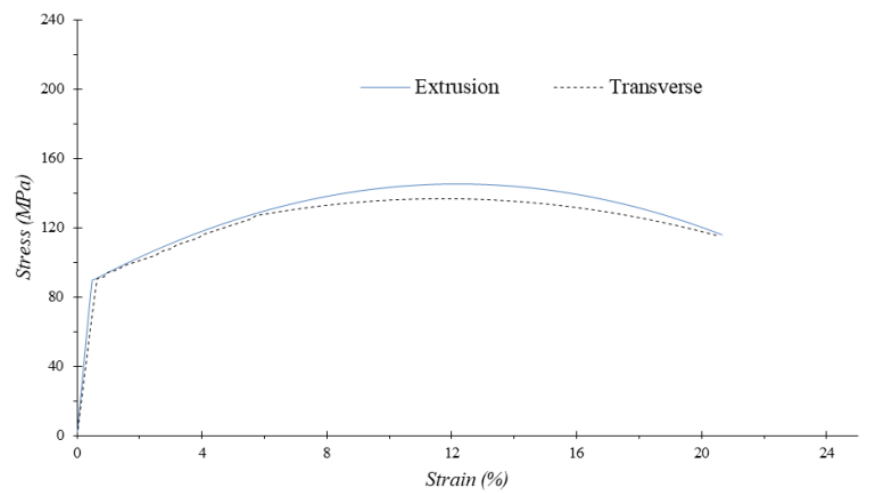

(c)

Figure 5: (a) Tensile samples cutting (b) Tensile test Experimental setup (c) True stress-strain $(\boldsymbol{\sigma}-\boldsymbol{\varepsilon})$ curves and material properties of AL6060-T4 


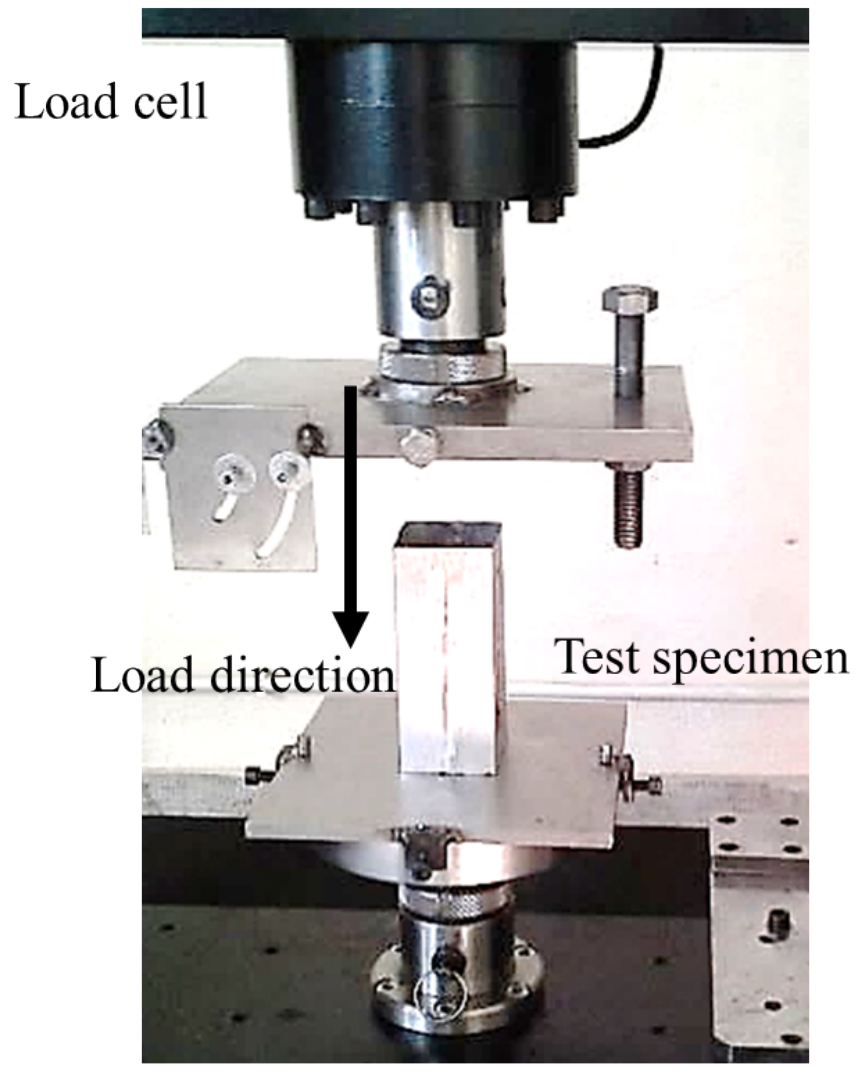

(a)
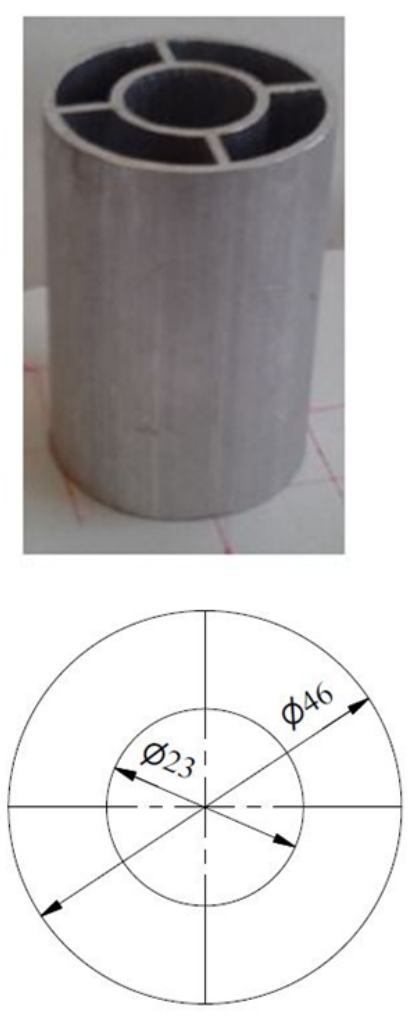

(b)

Figure 6: (a) Experimental test setup used for validation study where (b) Details of simple and nested specimens. (dimensions in $\mathrm{mm}$ ) 


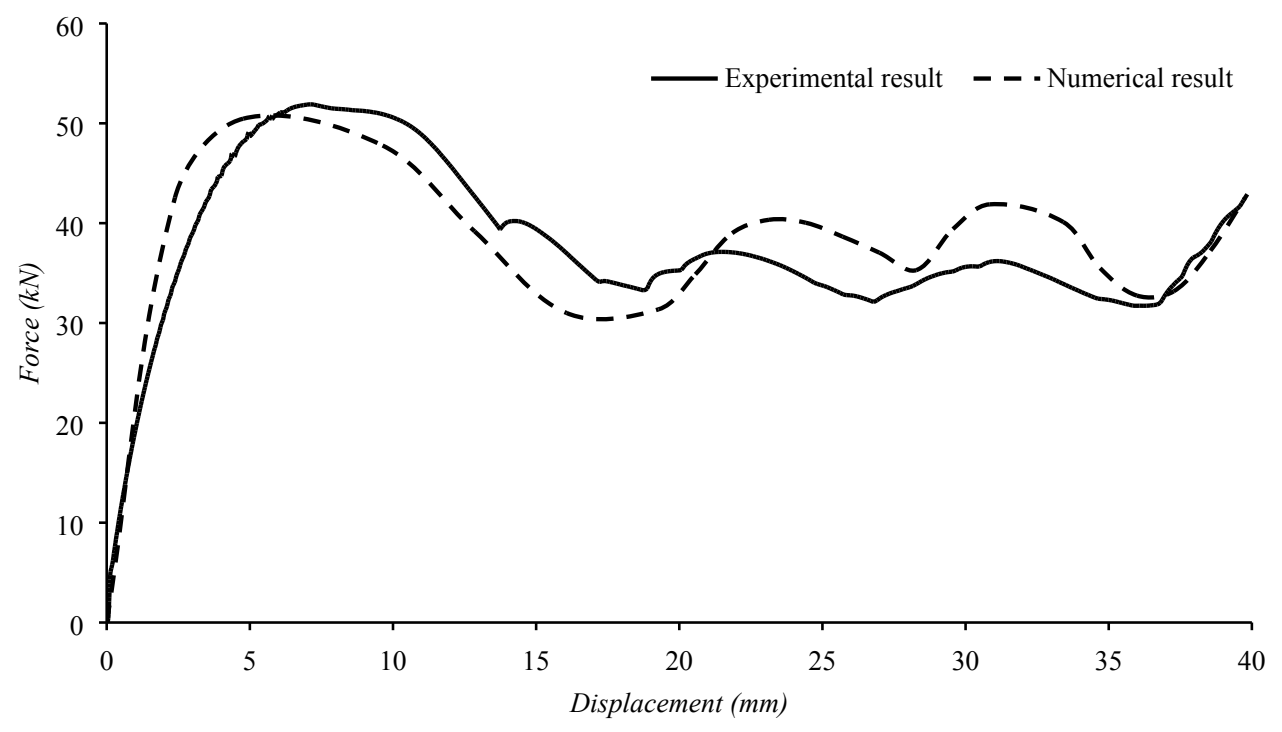

(a)
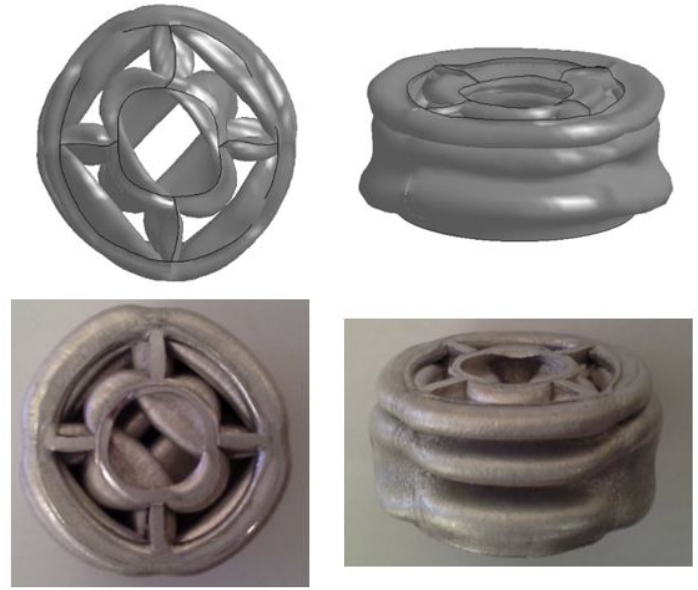

(b)

Figure 7: Comparison of experimental and numerical results (a) force-displacement curves and (b) deformation modes. 


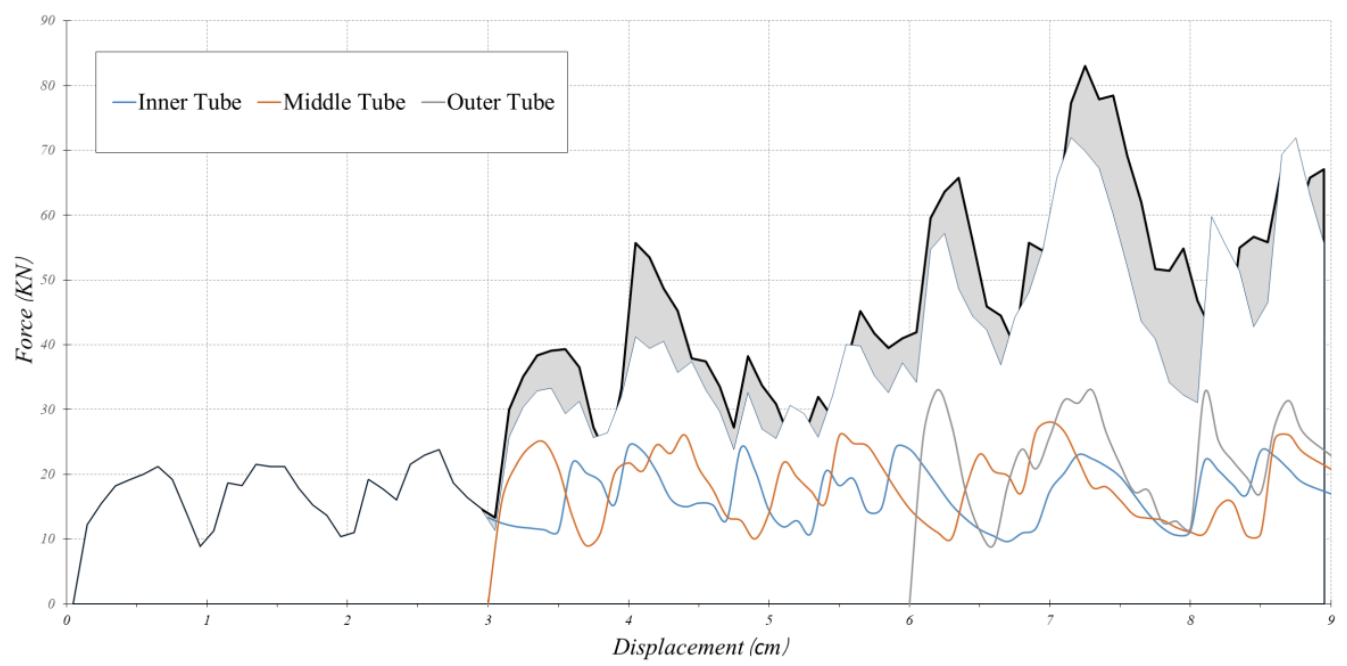

(a)

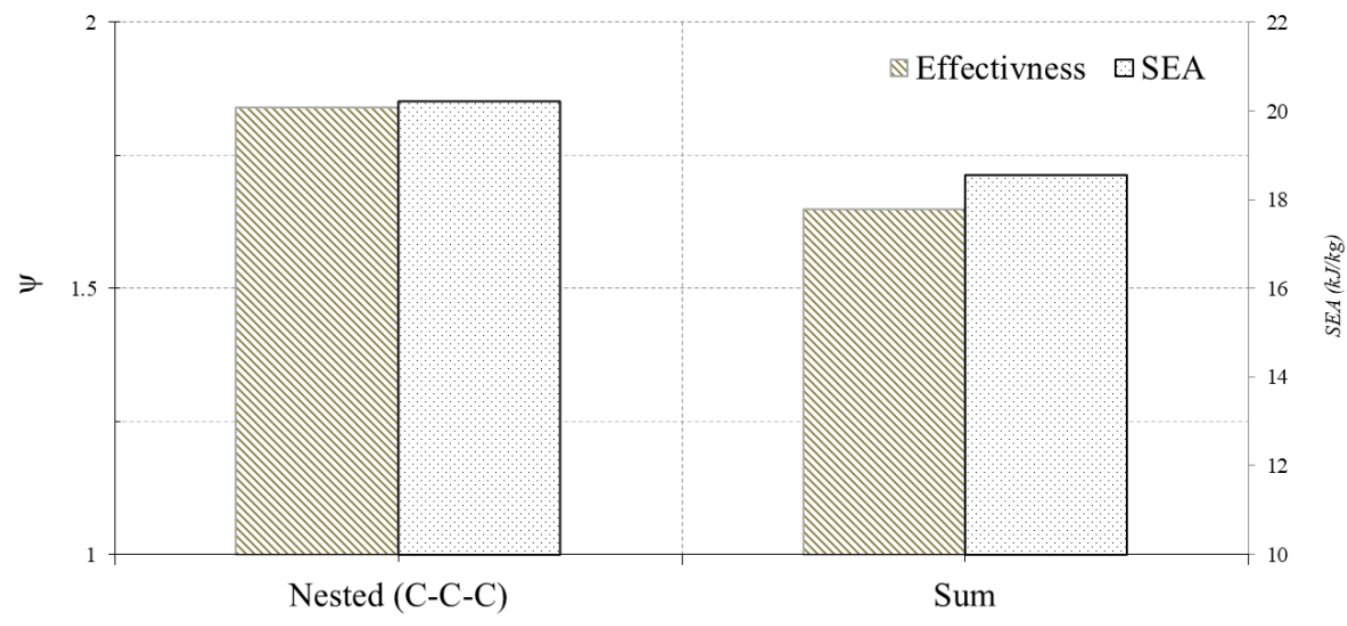

(b)

Figure 8: (a) Force-displacement curves, (b) crashworthiness metrics of nested and separate circular tubes 


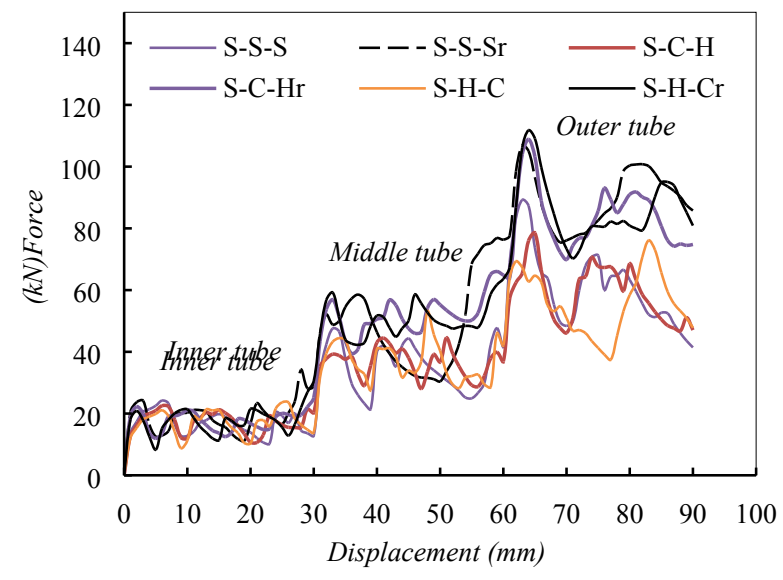

(a) Circular

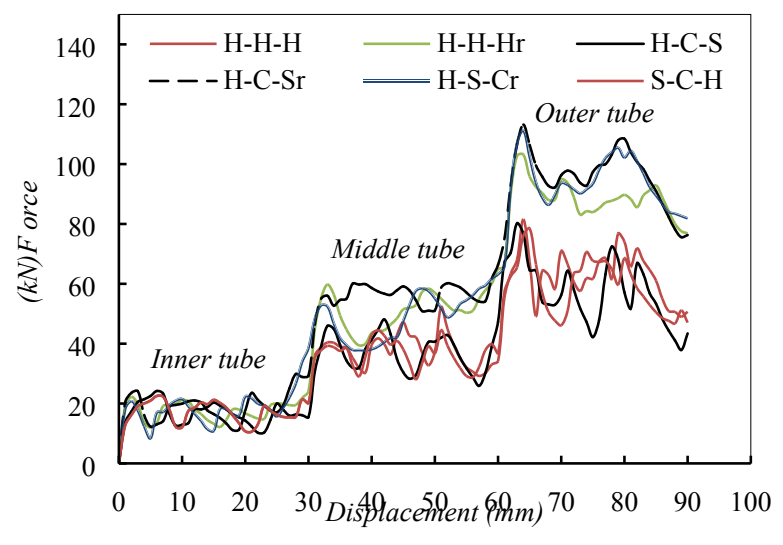

(b) Hexagonal

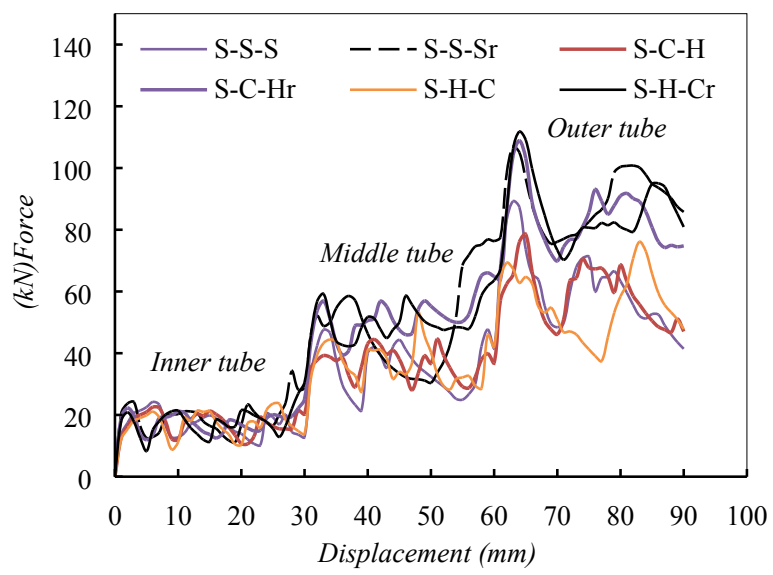

(c) Square

Figure 9: Force-displacement curves (a) circular outer tube, (b) hexagonal outer tube, (c) square outer tube. 


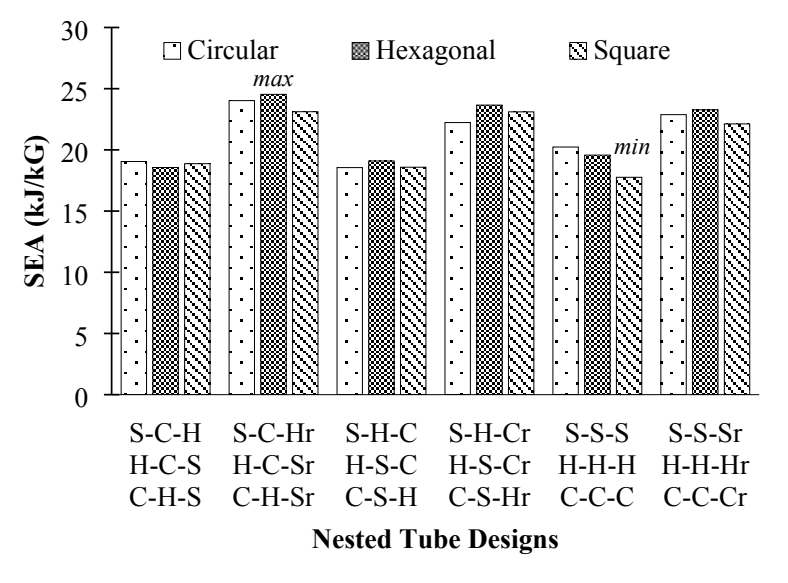

(a)

(c)

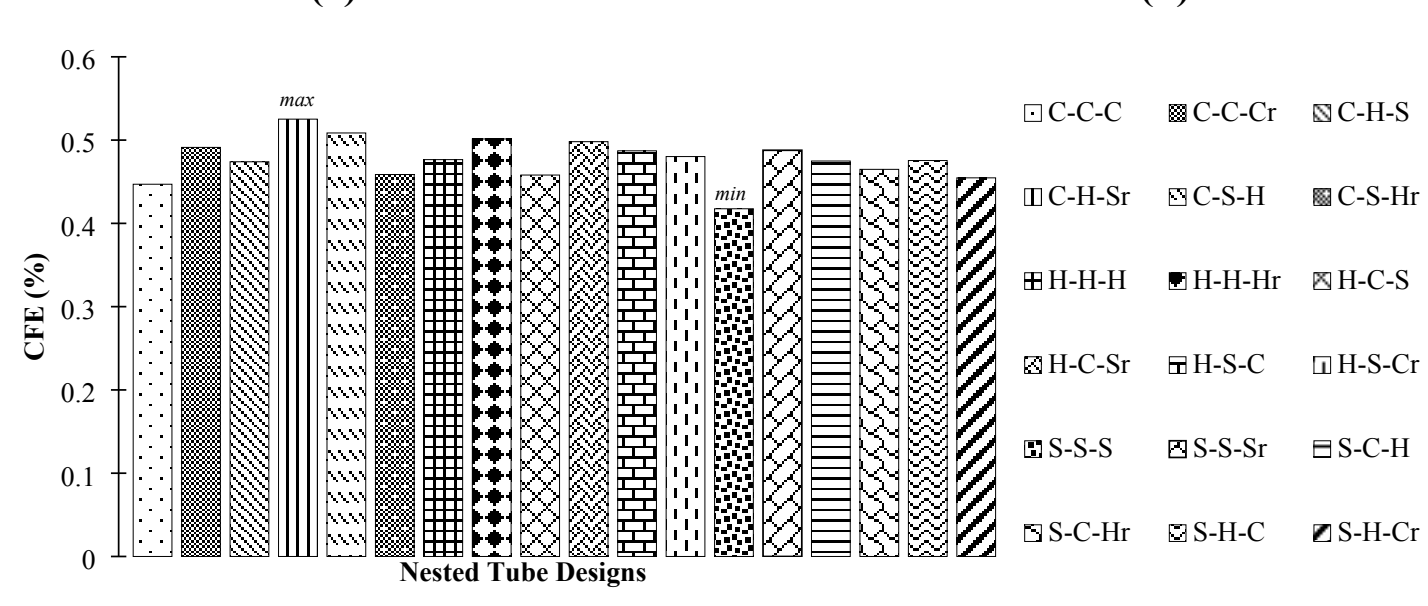

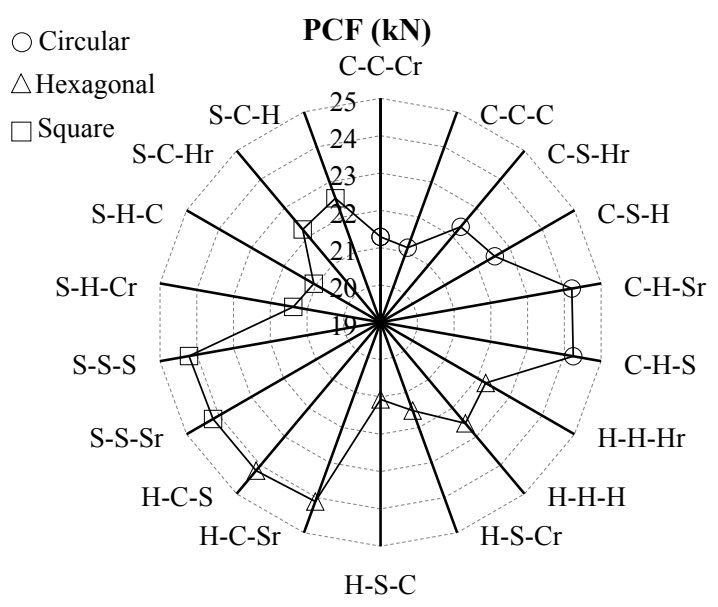

(b)

Figure 10: Crush performance of the nested tube designs (a) SEA, (b) PCF, (c) CFE 

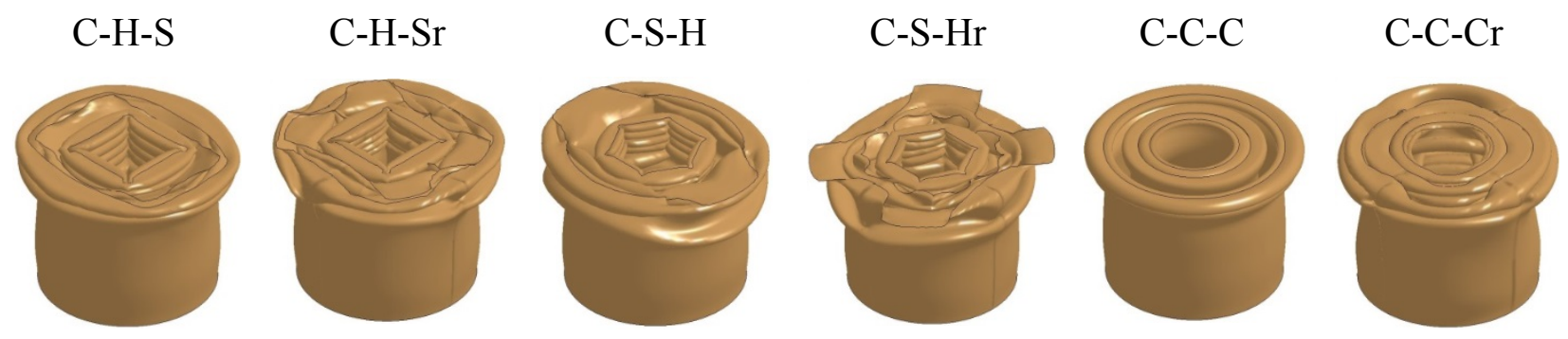

(a) Circular
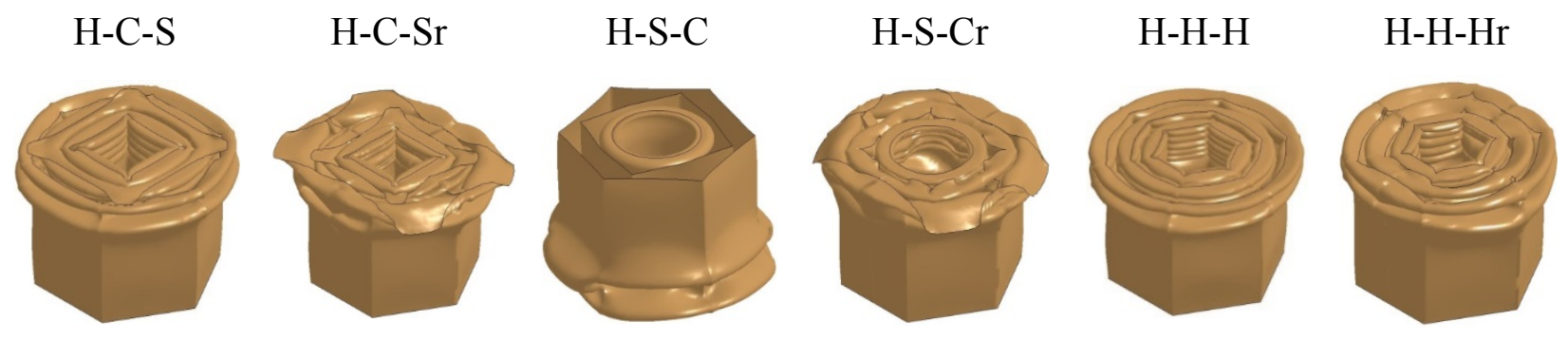

(b) Hexagonal
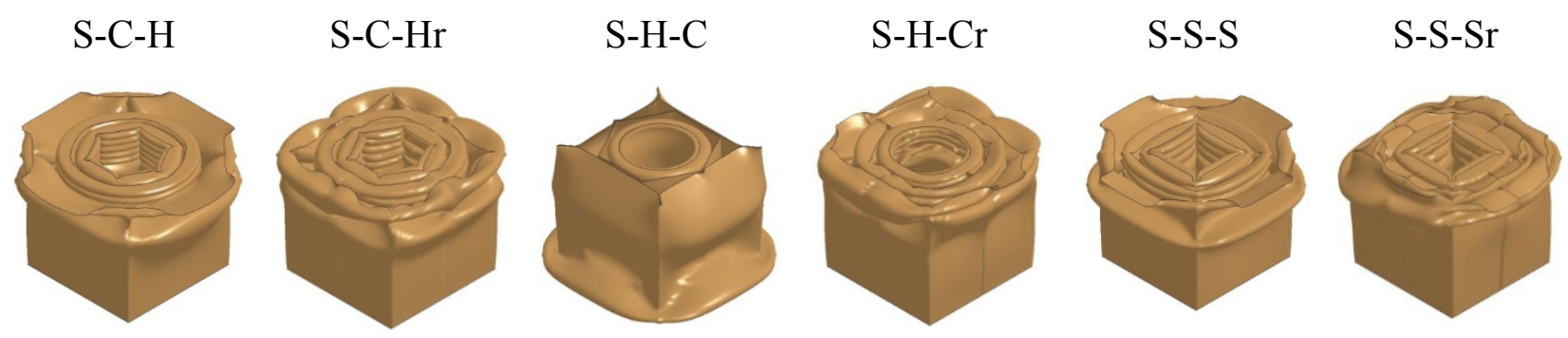

(c) Square

Figure 11: Deformed shapes of Haversian inspired nested tube designs (a) circular group, (b) hexagonal group, (c) square group. 